\title{
Gait Disorders in Older Adults
}

\author{
Neil B. Alexander, $M D$
}

$\mathrm{B}_{\mathrm{a}}^{\mathrm{o}}$ oth aging and diseases that are more prevalent with aging affect how older adults walk. This review addresses the evaluation and treatment of gait disorders in older adults. The focus is on comfortable gait, the most common clinically evaluated aspect of walking.

\section{GAIT AND DISABILITY}

From 8 to $19 \%$ of noninstitutionalized older adults have difficulty walking or require the assistance of another person or special equipment to walk. ${ }^{1,2}$ Walking disability increases with age. For example, $6 \%$ of female East Boston respondents aged 65 to 69 , compared with $38 \%$ of those aged 85 and older, need assistance in walking. ${ }^{3}$ Limitations in walking can be seen in as many as $63 \%$ of nursing home residents. ${ }^{4}$ In older adults with diseases such as arthritis, $35 \%$ admit to difficulty in walking one-quarter mile. ${ }^{5}$

Measures such as gait speed provide an index of functional status. Even in those who report no difficulty in walking one-half mile, a timed 8-foot walk, in addition to other lower-extremity function tests, ultimately predicts mobilityrelated and ADL disability at 4-year follow-up. ${ }^{6}$ Self-selected gait speed predicts self-perceived physical function, as measured by the Sickness Impact Profile (SIP), better than other physical measures such as balance and grip strength, particularly among frail nursing home residents. ${ }^{7}$ Prolonged 50 foot walk time relates to increased arthritis activity, although improvements in symptoms and signs predict walk time improvement inconsistently. ${ }^{8,9}$ Walking speed is particularly important for crossing traffic intersections safely. In a 1994 study, $27 \%$ of 592 older adult pedestrians were unable to reach the opposite curb before the light changes to allow cross traffic to enter the intersection. ${ }^{10}$ Finally, faster gait speed on admission predicts success in rehabilitation, ${ }^{11}$ and slow gait speed on discharge predicts institutionalization. ${ }^{12}$ Fifty-four percent of those requiring skilled care compared with none of those discharged home or to nonskilled levels of care have discharge walking speeds below $0.15 \mathrm{~m} / \mathrm{sec}^{12}$

Gait speed assessment is particularly useful in patients with cardiopulmonary disease. ${ }^{13,14}$ Self-paced 6-minute walking distance discriminates between NYHA levels of congestive heart failure ${ }^{15-17}$ and predicts hospitalization rates

From the Department of Internal Medicine, Division of Geriatric Medicine, at the University of Michigan, and the Geriatric Research Education and Clinical Center at the Department of Veterans' Affairs Medical Center, Ann Arbor Michigan.

Supported by National Institute on Aging Grants AG00519, AG10542, and $A G 08808$ and Rehabilitation Research and Development Grant E760RA from the Department of Veterans Affairs.

Address correspondence to Neil Alexander, MD, Geriatrics Center, 300 North Ingalls Building, Ann Arbor, MI 48109-0405. and mortality attributable to congestive heart failure. ${ }^{15} \mathrm{Com}$ fortable walking speed is a better predictor of cardiac index and functional status in patients with chronic heart failure and lung disease than treadmill or cycle ergometry exercise testing. ${ }^{18,19}$ In patients with chronic lung disease, 6- and 12-minute walking tests are useful measures of response to exercise training and medication adminstration in most, ${ }^{19-23}$ but not all, ${ }^{24,25}$ studies. The relationship between walking tests and pulmonary function tests are, however, inconsistent, ${ }^{26-28}$ and there may also be a practice effect in walk time. ${ }^{27-29}$

Other gait measures also correlate with functional outcome. Walking cadence, as measured by the number of steps walked per minute, correlates with SIP scores. ${ }^{30}$ Stride length and the symmetry of swing duration in the unaffected versus the affected leg correlate well with extent of motor recovery in hemiplegic patients. ${ }^{31,32}$ (See Figure 1 for a graphic representation of some of the temporal and spatial measures of gait).

\section{FACTORS INFLUENCING GAIT}

\section{Age-Related Factors}

Although comfortable gait speed may decline at a rate of $0.2 \%$ per year up to age 63 , speed decline accelerates up to $1.6 \%$ per year after age 63 in subjects relatively free of orthopedic, cardiorespiratory, neurological, or cognitive problems. ${ }^{34,35}$ Bendall et al. ${ }^{36}$ reported a lower rate of decline from age 65 to $90,0.7 \%$ per year, but this study includes few subjects older than age 80 . The age-related decline in gait speed is apparently the result of a decrease in step or stride length ${ }^{37,38}$ rather than a decrease in cadence. Results from a number of studies ${ }^{34,36-51}$ that examine the effect of advanced age on gait speed are illustrated in Figure 2. Individual studies that include more than one age grouping are connected by a line. Gait speed may be reduced in studies that include older adults with diseases, ${ }^{36,43,46}$ where data acquisition apparatus is attached to the lower extremities, ${ }^{38,41}$ or where the walk task involves turning or walking along a line. ${ }^{52}$

Other characteristics of gait change with aging. Declines in older adult step length, stride length, ankle range of motion, vertical center of pressure excursion, and pelvic obliquity are found in women ${ }^{42}$ but, except for pelvic obliquity, not in men. ${ }^{39}$ Shorter, broader strides, decreased vertical and increased horizontal head excursions, decreased limb excursions, longer stance and shorter swing durations (and subsequent decreased swing to stance ratio), and slower cadence are most apparent after age 75 or $80.44,48$ Older adults are more likely to exhibit decreased push-off power and a more flat-footed landing. ${ }^{53}$ Classically, these changes are illustrated in Figure 3, the old adult gait pattern on the left, young 


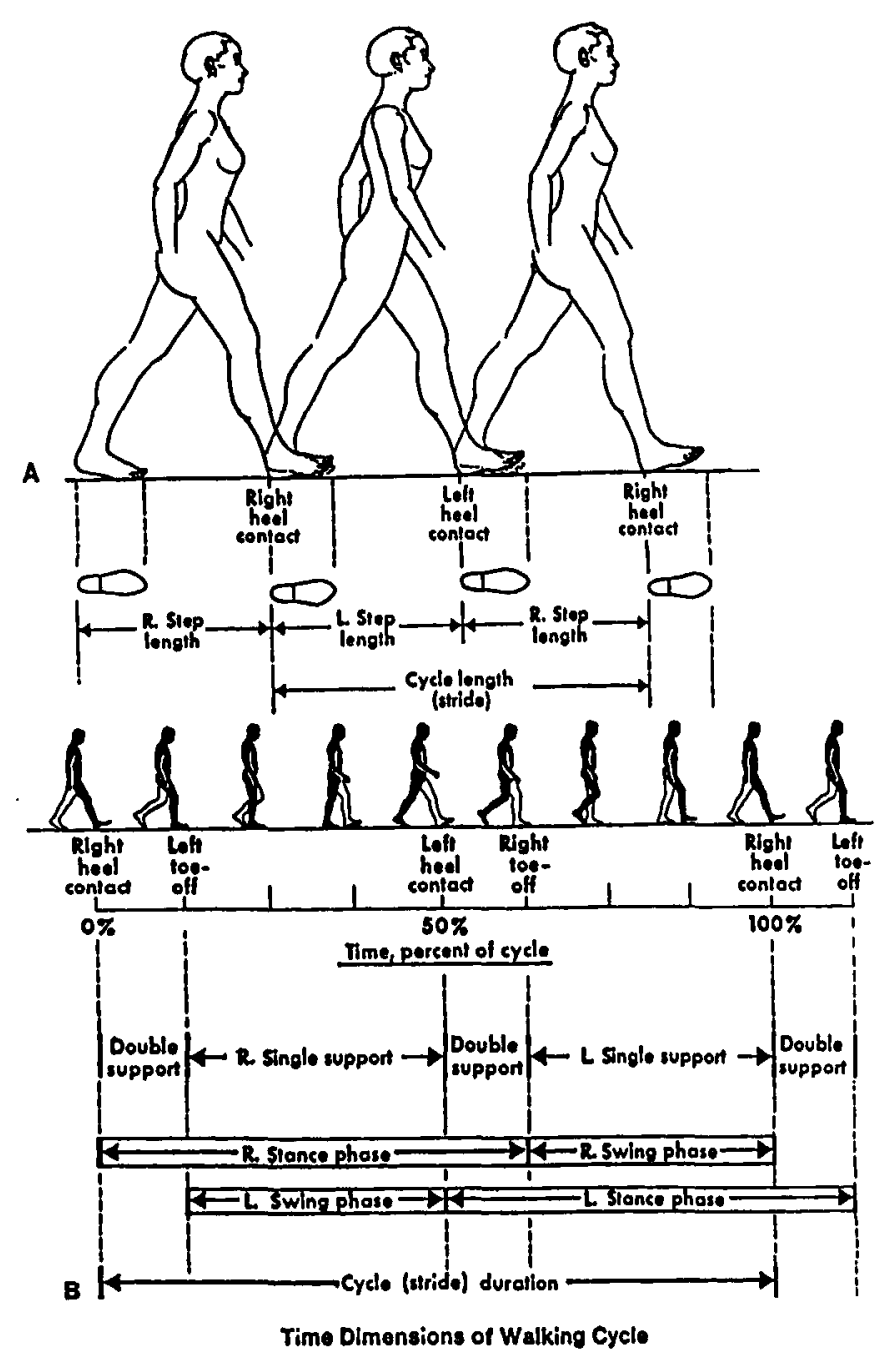

Figure 1. Distance and time dimensions of the walking cycle ${ }^{33}$ (reprinted with permission).

adult on the right. However, the differences in most temporalspatial, joint motion, and other biomechanical measures between young adults and healthy older adults (mean age approximately 70 or less) are generally less than $30 \%$ and often less than $10 \% 37-39,42,44,47,48,50,53-55$. Thus, Figure 3 seems to exaggerate these young-old differences.

Because these gait characteristics depend on gait speed, perhaps the young-old differences are the result of the agerelated speed decline. ${ }^{56}$ For example, as speed slows, the excursions of the head (vertically) and limbs are generally reduced, while lateral head excursion is increased. ${ }^{57,58}$ When controlling for velocity and for subject height, there are minimal ${ }^{59}$ or no apparent young-old gait differences, especially in older adults aged 60 to $75 .^{55,60}$

Why might gait velocity and stride length decrease with age? Some speculate that subtle changes in musculoskeletal function, such as stiffness and strength loss or changes in energy expenditure or conservation strategies, limit the ability to achieve a faster comfortable speed. ${ }^{37,61}$ Many believe that decreased speed and stride length allow increased double support time and thus improved bipedal balance, ${ }^{48}$ i.e., a safer and more stable gait pattern. ${ }^{5.3}$

\section{Anthropometry and Gender}

Subject characteristics may confound the age-associated decline in gait speed. Height is correlated with gait speed independent of agc $^{34,36,52}$ because taller subjects are known to have greater step and stride lengths. ${ }^{62}$ However, at least in some studies, ${ }^{63}$ the percentage of variance explained by height $(12 \%)$ or leg length $(6 \%)$ is overshadowed by the age $(33 \%)$ effect. Older women may walk more slowly than men, ${ }^{36}$ and yet the age-related speed decline after age 63 may accelerate more in men ( $16.1 \%$ per decade) than in women (12.4\% per decade). ${ }^{34}$ When controlling for leg length and compared with young adults, speed declines in healthy old women ${ }^{42}$ but not in healthy old men $^{39}$; note that the old women were somewhat older than the old men. Others find no gender difference when measures are controlled for height. ${ }^{37}$

\section{Disease}

Musculoskcletal, neurological, and cardiorespiratory symptoms are associated with decreased gait speed, ${ }^{36,52}$ particularly for fast pace walking. ${ }^{46}$ This disease-related slowing appears to be related mainly to declines in stride length ${ }^{43}$ and is common in older adults hospitalized with acute illnesses. ${ }^{64}$ Gait alterations such as diminished stride length, increased double limb support, reductions in limb range of motion, stepping variability, and reductions in foot-floor clearance are common in patients with a variety of diseases such as Parkinson's disease, ${ }^{65-68}$ hemiplegia/hemiparesis, ${ }^{31,67,69-72}$ normal pressure hydrocephalus, ${ }^{73-75}$ diabetic neuropathy, ${ }^{76}$ knee and hip osteoarthritis, ${ }^{67,77-79}$ and congestive heart failure. ${ }^{80,81}$ These gait alterations increase with increasing severity of diseases, particularly in Parkinson's disease ${ }^{68,82}$ and knee osteoarthritis. ${ }^{83}$ Pain caused by hip and knee osteoarthritis may lead to many of these gait alterations as well as unique uneven forward progression, lateral lurching, and asymmetry (antalgic gait). ${ }^{83-85}$

\section{Leg Function}

Leg extensor power is associated strongly with selfselected rapid gait speed (Pearson's $r=.6-.9$ ) in those who are very old (mean age 87 ) and frail. ${ }^{86}$ Note that the speed increase plateaus with additional leg power available. ${ }^{86}$ Furthermore, self-selected comfortable gait speed is less strongly associated with leg (plantar flexion) strength (Pearson's $r=.4$ ) in younger (mean age 72 ), less frail older adults. ${ }^{36,87}$ Others believe that the relationship between leg strength and gait is curvilinear ${ }^{88}$ so that beyond a certain level of strength, gait performance improvements, such as in gait speed, are less striking. Determining the importance of strength is complicated by the fact that static, isolated tests of strength at one joint used commonly in these studies may not reflect the strengths required during walking, a multi-joint, dynamic task. ${ }^{56}$ Finally, greater passive range of motion (ROM) in the legs, particularly in ankle plantarflexion and dorsiflexion and hip extension, is associated with faster gait speed. ${ }^{63}$ Strength and joint range of motion also predict gait changes in certain disease conditions such as hemiplegia ${ }^{89,90}$ and diabetic neuropathy. ${ }^{76}$

\section{Cognitive and Affective Function}

Gait speed correlates with cognitive and affective function. ${ }^{7.52}$ Compared with patients with higher Folstein Mini- 


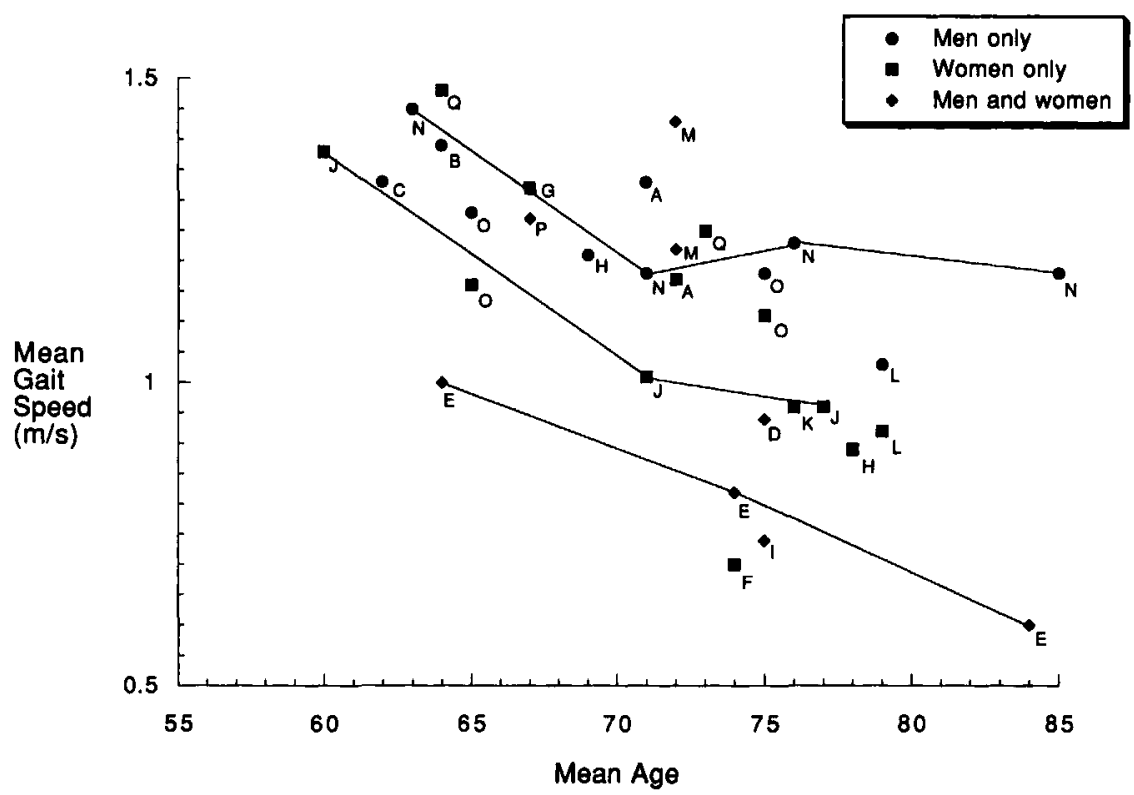

Figure 2. Mean comfortable gait speeds in older adults, according to mean age per study series, grouped according to men only, women only, or men and women together. Studies that include more than one age grouping are connected by a line. Each series is identified by a letter according to the following code: $A^{36}, B^{39}, C^{40}, D^{37}, E^{38}, F^{41}, G^{42}, H^{34}, I^{43}, J^{44}, K^{45}, L^{46}, M^{47}, N^{48}, O^{49}, P^{50}, Q^{51}$.

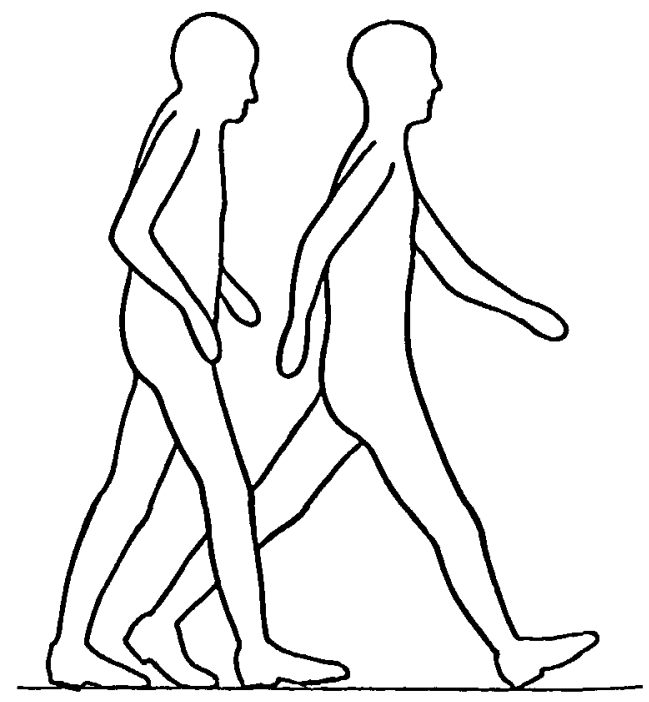

Figure 3. Apparent age-related differences in sagittal body position of healthy old (left) and young (right) men at the instant of heel strike ${ }^{48}$ (reprinted with permission).

Mental State (MMS) scores, ${ }^{91}$ patients with MMS scores $\leq$ 16 walk $20 \%$ more slowly on admission to a rehabilitation unit and tend not to increase their gait speed as much by the time of discharge. ${ }^{11}$ Compared with age-matched controls, patients with probable Alzheimer's disease walk 30 to $40 \%$ more slowly, with shorter steps, lower stepping frequency, and higher double support ratio. ${ }^{92,93}$ Gait speed slows and step-to-step variability increases with increased severity of the dementia ${ }^{93}$. Patients with clinically diagnosed depression walk more slowly and with decreased foot push-off, described as a "pulling" rather than "propelling" gait". These gait findings also correlate strongly with depressive symptomatology on standard screening tools such as the Geriatric Depression Scale ${ }^{95}$ and the Beck Depression Inventory, ${ }^{96}$ and some suggest that gait speed could serve as a marker for psychomotor retardation. ${ }^{96}$ Other behavioral factors are also important, as evidenced by the approximate $8 \%$ increase in 6-minute walking distance achieved by giving patients with cardiac and pulmonary disease verbal encouragement. ${ }^{97}$

\section{Activity and Exercise}

Lower daily activity level is associated with slower gait speed. ${ }^{36,52}$ Compared with people with unlimited outdoor activity, frail older adults who are housebound and/or get out infrequently walk more slowly, have reduced stride length, step frequency, and turning time and increased stance/swing ratio and double support time. ${ }^{43}$ Note that housebound adults are more likely to use assistive devices, primarily canes, that can also slow gait.

On the other hand, the age-associated decline in gait speed may be mitigated by physical conditioning. In younger old men (aged 55-66), some of whom are active in vigorous physical activity, self-selected (especially rapid pace) gait speed is independent of age and instead is associated with increased maximum oxygen uptake, i.e., cardiovascular fitness. ${ }^{40}$ Some studies find increased (up to $17 \%$ ) comfortable gait speed in healthy active versus sedentary older adults, ${ }^{47}$ whereas others find minimal speed difference. ${ }^{45}$

In community-dwelling older adults who are essentially free of medical conditions that might cause a gait disorder, exercise may improve comfortable gait speed, but the effect is modest. Low-impact aerobic dance can improve the time to walk one-half mile by up to $13 \% .{ }^{98}$ In generally healthy older community-dwelling participants (aged 75 or older), improvement in usual gait speed is small whether subjects undergo 3 months of resistance training (7\% improvement) or balance training ( $3 \%$ improvement). ${ }^{99}$ Life-care community members (mean age 82 ) improve their usual gait velocity by $8 \%$ after participating in a combined resistance-balance training program. ${ }^{100}$ Other low-intensity strength-flexibility 
and dynamic resistance training programs have a minimal effect on gait velocity and step length. ${ }^{101,102}$

Similar effects are seen in frail older aduits. Eight weeks of resistance training resulted in no significant change in habitual gait speed in frail institutionalized volunteers, ${ }^{103}$ but two of the 10 participants no longer used canes to walk. In a follow-up controlled study, gait speed improved $9 \%$ (from $0.51 \mathrm{~m} / \mathrm{s}$ at baseline to $0.55 \mathrm{~m} / \mathrm{s}$ ) in those who underwent 10 weeks of resistance training, ${ }^{104}$ and four subjects reduced their dependency from a walker to a cane. In response to strength and aerobic training, nursing home-residing veterans who had muscular weakness but were not dependent on an assistive device showed similar improvements. ${ }^{105}$

\section{Falls and Fear of Falling}

Gait disorders are common risk factors for falls $\left({ }^{106,107}\right)$. Losing one's balance and/or having a sense of unsteadiness are related directly to measures such as reduced gait velocity and increased trunk accelerations while walking, i.e., decreased walking smoothness. ${ }^{108,109}$ Sometimes it is unclear if a gait disorder leads to a fall or if a fall leads to a gait disorder. ${ }^{110}$ Compared with hospitalized non-fallers, hospitalized fallers walk at a slower speed and with shorter and more variable step lengths and cadences, even with the exclusion of subjects with fracture and musculoskeletal or neurological disorders. ${ }^{64}$ One-quarter of hospitalized fallers who have slow stepping frequency and variable step lengths are described as anxious and wanting to maintain their motions within a small support base. ${ }^{64}$ In a mixed group of hospitalized and community-dwelling older adults, persons who fell in the last year walked more slowly and had a shorter stride length. ${ }^{43}$ Slower gait speed is also seen in nursing home fallers compared with nursing home controls. ${ }^{111}$ Yet, as long as both fallers and non-fallers are relatively healthy, live in the community, and are not hospitalized, there are few faller/ non-faller differences in gait variables such as step width, stride length, single and double support time, and joint motions while walking. ${ }^{112-114}$ Part of the problem in relating falls to gait disorders may be the nature of the fall history. Gait speed and stride length are more strongly related to self-assessed tendencies to fall than falls reported in the past year. ${ }^{95}$

Perhaps fear of falling and fall-related self efficacy correlate more highly with gait measures than with reports of falls. ${ }^{115}$ Some patients may suffer a fall without a fracture and subsequently be apprehensive or stagger while walking, tending to clutch and grab for support, i.e., the "post-fall syndrome."116 Rarely, patients may exhibit "space phobia," with such fear of falling that they cling to support objects such as walls. ${ }^{117}$

\section{SPECIFIC GAIT DISORDERS}

Determining that a gait is "disordered" is difficult because there are generally no clearly accepted standards of "normal" gait for older adults. ${ }^{56}$ Some believe that slowed gait speed suggests a disorder, while others believe that deviations in smoothness, symmetry, and synchrony of movement patterns suggest a disorder (see section on gait disorder evaluation). Attributing a gait disorder to one etiology is also difficult because similar gait abnormalities are common to many diseases. ${ }^{56}$

Underlying medical conditions are major contributors to gait disorders. In a group of community-dwelling adults older than age $88,61 \%$ reported one or more diseases or symptoms as causing gait impairment, ${ }^{118}$ most commonly joint pain, followed by multiple causes including stroke, visual impairment, and back or neck pain. Many reported more than one contributing cause. Of those who reported no specific disease-related abnormality of gait, ${ }^{118}$ many had abnormalities on examination, such as impaired sensory function in the legs $(36 \%)$ and difficulty walking tandem $(52 \%)$, and on gait screening. ${ }^{119}$

Older adult patients included in published series tend to be referred for a gait disorder of unknown etiology. Sudarsky et al. ${ }^{120}$ examined a series of sequential neurological referrals for undiagnosed gait disorders $(\mathrm{n}=50$, mean age 80, age range not given), and Fuh et al. ${ }^{121}$ classified 50 inpatients (mean age 66 , age range $50-78$ ) presenting to an inpatient neurological unit with a chief complaint of difficulty walking. Patients with paralyzing strokes, known Parkinson's disease, severe hip or knee disease, and major tranquilizer use are excluded. Presumably, many gait disorders, particularly those that are classical and discrete (such as antalgic gait) and those that are mild and/or may relate to irreversible disease (such as multi-infarct dementia), are diagnosed and treated by the primary care physician with no additional referral. One exception is a family practice series, where Hough et al. ${ }^{122}$ included 35 patients (mean age not given, age range 65-89) with self-reported difficulty in walking, but excluded anyone hospitalized or who had sustained trauma in the past 6 weeks. Table 1 illustrates the type, number, and percentage of diagnoses made in each series, and a discussion of these diagnoses follows.

\section{Parkinson's Disease}

From 10 to $12 \%$ of the Sudarsky ${ }^{120}$ and Fuh ${ }^{121}$ series had their gait disorder attributed to idiopathic Parkinson's disease and related syndromes such as drug-induced parkinsonism and progressive supranuclear palsy. Parkinson's disease is usually cited as a cause of a gait disorder when standard disease criteria are fulfilled, such as bradykinesia, rigidity (cogwheel), tremor, and a flexed posture, and often in the setting of a positive response to levodopa treatment. ${ }^{120}$

\section{Vascular-Related Disorders}

Patients with major deficits secondary to a cerebrovascular accident are generally excluded in gait disorder series. In Sudarsky's series, ${ }^{120} 16 \%$ of those with an abnormal gait had evidence of cerebral infarcts on CT scan but no history of hemiparesis or major motor deficit from a stroke. In Fuh's series, ${ }^{121}$ the rate of multiple infarcts and Binswanger's disease (discussed below) is even higher, up to $28 \%$. Based on a retrospective review, gait disturbances are seen in $27 \%$ of patients with multi-infarct dementia, often 2 years before the diagnosis of overt dementia is made. ${ }^{123}$ The gait disorder described by Kotsoris et al. ${ }^{123}$ is either hemiparetic, Parkinsonian, ataxic, or nonspecific (short-step, narrow base, slightly spastic, with a shuffling or "glue-footed" quality).

Smaller vessel periventricular and deep white matter changes, which may be attributed to chronic ischemia (also referred to as leukoaraiosis), ${ }^{124}$ may also contribute to gait disorders. ${ }^{125-127}$ Furthermore, a group of nursing home fallers with apparent impairments in gait and balance exhibited significantly more white matter hypodensity on CT scan than did nursing home controls. ${ }^{128}$ The problem is that leukoaraiosis has been found in as many as $19 \%$ of head CT scans and 
Table 1. Diagnoses in Older Adults Presenting with Gait Disorder (\% of group)

\begin{tabular}{|c|c|c|c|}
\hline \multirow{3}{*}{$\begin{array}{l}\text { Primary Diagnoses Contributing to } \\
\text { Gait Disorder }\end{array}$} & \multicolumn{3}{|c|}{ Series } \\
\hline & \multicolumn{2}{|c|}{ Neurologic Referral } & \multirow{2}{*}{$\begin{array}{l}\text { Primary Care } \\
\text { Hough }^{122}\end{array}$} \\
\hline & Sudarsky ${ }^{120}$ & Fuh $^{121}$ & \\
\hline Frontal gait disorder (gait apraxia) & 20 & 28 & 0 \\
\hline Normal-pressure hydrocephalus & 4 & & \\
\hline $\begin{array}{l}\text { Multiple strokes/Binswanger's } \\
\text { disease }\end{array}$ & 16 & 28 & \\
\hline Sensory imbalance & 18 & 4 & $\boldsymbol{9}$ \\
\hline $\begin{array}{l}\text { Neuropathy } \\
\text { Multiple sensory deficits }\end{array}$ & & 4 & 3 \\
\hline Myelopathy & 16 & 24 & 0 \\
\hline $\begin{array}{l}\text { Cervical spondylosis } \\
\text { Vitamin B12 deficiency }\end{array}$ & & 22 & \\
\hline Parkinsonism & 10 & 12 & 9 \\
\hline Idiopathic Parkinson's disease & 10 & $\begin{array}{r}12 \\
8\end{array}$ & 9 \\
\hline Drug-induced parkinsonism & & & \\
\hline Progressive supranuclear palsy & & 2 & \\
\hline Cerebellar atrophy & 8 & 8 & 0 \\
\hline Other & 14 & 16 & 79 \\
\hline Tumors & 2 & 6 & \\
\hline Depression & 2 & & \\
\hline Motor neuron disease & & 2 & \\
\hline Lumbar stenosis & & 2 & \\
\hline Alzheimer's disease & & 4 & \\
\hline $\begin{array}{l}\text { Degenerative joint disease/gouty } \\
\text { arthritis }\end{array}$ & 4 & & 43 \\
\hline Orthostatic hypotension & 2 & & 9 \\
\hline Intermittent claudication & & & 6 \\
\hline Post-cerebrovascular accident & & & 6 \\
\hline Congenital deformity & & & 6 \\
\hline Post-orthopedic surgery & & & 3 \\
\hline Vertebrobasilar insufficiency & & & 3 \\
\hline Heart disease/heart failure & 2 & & 3 \\
\hline Toxic/metabolic encephalopathy & 2 & 2 & \\
\hline $\begin{array}{l}\text { Essential ("senile") gait disorder } \\
\text { Number of diagnoses contributing } \\
\text { to gait disorder }\end{array}$ & 14 & 6 & 3 \\
\hline Single diagnosis above & 56 & NA & NA \\
\hline Combinations of diagnoses above & 28 & NA & 75 \\
\hline
\end{tabular}

92\% of MR scans in apparently healthy "normal" older adults (as reviewed in Meyer ${ }^{129}$ ). The inability to perform tandem gait or walk a straight line is associated with increased T2 signal intensity on MR scans, indicative of white matter abnormalities. ${ }^{130}$ This relationship is evident, however, only in relatively larger and severely abnormal signals, such as multiple foci or large confluent patches. The problem is that the severity of the MR scan abnormalities, like the most profound gait abnormalities, increase with age, suggesting a possible age confound. Perhaps only periventricular and white matter changes on T2-weighted MR scans that are excessive for age are associated with clinically significant disease, such as ischemic vascular dementia. ${ }^{131}$

In a special case of leukoaraiosis, termed subcortical arteriosclerotic or vascular leukencephalopathy of the "Binswanger type," white matter lesions from small vessel disease involve the basal ganglia or periventricular white matter, particularly in patients with hypertension. ${ }^{132,133}$ At least half of the patients with this condition ${ }^{132}$ have elements of a frontal gait disorder, namely slow, wide based gait, hesitation in starting, shuffling, freezing, small steps ("marche a petits pas"), difficulty in picking their feet off the floor ("magnetic foot" response), and difficulty with turns. ${ }^{134-136}$ The most severely affected patients develop poor truncal balance, are unable to initiate a step, and are unable to stand up without support. ${ }^{136}$ Others have described pyramidal, extrapyramidal, ataxic, and apractic gait. ${ }^{1.37}$ Despite their gait disorder, all patients are able to perform simple leg tasks when seated or lying, suggesting an element of gait apraxia. ${ }^{136}$

Concurrent cognitive impairment likely confounds these vascular-related gait disorders. Stepping variability may be present in patients with probable vascular-related dementia, although only $29 \%$ of these demented patients exhibit clini- 
cal gait abnormalities (short, slow steps, difficulties in turning with postural instability). ${ }^{126}$ Half of the subjects with cerebral infarcts on CT in Sudarsky's series ${ }^{120}$ are demented, and most Binswanger's patients have mental status abnormalities. ${ }^{132,133,136}$ In patients with atherosclerotic white matter disease, Masdeu et al.'s review ${ }^{128}$ suggests that cognitive impairment develops before or simultaneously with the onset of gait disorders in $37 \%$ of the cases identified. In $43 \%$ of the cases, the gait impairment precedes the cognitive impairment.

\section{Normal Pressure Hydrocephalus}

The diagnosis of normal pressure hydrocephalus (NPH) is based on the classical triad of dementia, unsteady gait, and urinary incontinence, with hydrocephalus on brain scan and a normal CSF pressure $(<180 \mathrm{~mm}) .^{138,139}$ The diagnosis is not as common as might be believed ${ }^{140}$ with a prevalence of $1 \%$ in a population screened for dementia. ${ }^{141}$ Diagnosis of NPH is rare in both the Sudarsky $^{120}$ series $(4 \%)$ and in the Fuh ${ }^{121}$ series (none). In an older study, ${ }^{142}$ as many as 50 of 109 presenting for gait evaluation were diagnosed with $\mathrm{NPH}$, and 17 of the 50 improved with shunting or CSF withdrawal, although the criteria for NPH diagnosis in this study has recently been questioned. ${ }^{143}$ The NPH gait ${ }^{142,144,145}$ is characterized by unsteadiness that progresses to short, shuffling, scuffing steps, slow and unsteady turning, and difficulty with gait initiation. Leg function is normal specifically for voluntary motor tasks when supine or nonweight bearing and becomes abnormal with weight bearing, ${ }^{146}$ suggesting similarities with frontal gait disorder and gait apraxia.

The diagnosis of NPH may be difficult because CT findings, such as ventricular enlargement and cerebral atrophy, are not necessarily diagnostic. ${ }^{147}$ Furthermore, CT scans in NPH patients may show multiple infarcts, ${ }^{139}$ whereas patients with multiple cerebral infarcts may have hydrocephalus. ${ }^{120}$ This suggests a possible overlap between the NPH and vascular etiologies and may account for the similarities in gait disorder presentation. Note that a history of hypertension is present in nearly all patients with $\mathrm{NPH},{ }^{120,139}$ and ventricular dilatation or frank hydrocephalus can accompany hypertensive cerebrovascular disease. ${ }^{136,148}$

\section{Sensory Abnormality}

Abnormalities in visual, vestibular, and proprioceptive function were associated with gait disorders and accounted for $18 \%$ of Sudarsky's group, ${ }^{120}$ excluding patients with myelopathy. Peripheral neuropathy was present in nearly all of this group and many had a positive Romberg's test. Complaints that might be vestibular-related (such as vertigo, leaning to the side, instability of the ground under their feet) were common. In the Fuh series, ${ }^{121}$ the two neuropathy patients apparently had motor involvement as well.

\section{Myelopathy}

Sixteen percent of Sudarsky's group ${ }^{120}$ fulfilled criteria for myelopathy, based on evidence of leg spasticity (spastic hypertonus and pyramidal signs), proprioceptive deficits, and positive findings on objective evaluation (such as on spine films, myelography, and Schilling test). Patients walk with stiff legs, reduced toe clearance, and a tendency toward circumduction. ${ }^{135}$ Common findings also include urinary frequency and urgency and a positive Romberg's test, al- though local pain and radicular symptoms may be absent. ${ }^{135}$ In the Fuh series, ${ }^{121} 22 \%$ had cervical myelopathy.

Patients with vitamin $B_{12}$ deficiency may present with a treatable myelopathy as well as peripheral neuropathy, dementia, and optic nerve atrophy. Early paresthesias give way to full loss of position sense (causing sensory ataxia, widebased tottering from side-to-side), weakness, and spasticity (causing spastic ataxia). ${ }^{149-152}$ In patients with $\mathrm{B}_{12}$ deficien$c y,{ }^{151}$ including subjects more than 80 years of age, ataxia of gait is an initial complaint or exam finding in approximately one-fifth, particularly in the setting of sensory losses. Anemia is not always present. Ataxia or abnormal gait may be found in $43 \%$ of patients with low (and sometimes low normal) serum cobalamin and normal hematocrit and/or mean cell volume. ${ }^{153}$ Although less common and less severe, folate deficiency may also result in a treatable myelopathy- and neuropathy-associated gait disorder, sometimes without anemia or macrocytosis. ${ }^{152,154,15.5}$

\section{Cerebellar Disorders}

In both the Sudarsky ${ }^{120}$ and Fuh ${ }^{121}$ series, $8 \%$ of subjects had cerebellar atrophy on CT scan in addition to truncal ataxia and other clinical features of cerebellar atrophy. Note that cerebellar atrophy, particularly of the vermis, may occur in older adults who exhibit no symptoms or signs of cerebellar disease. ${ }^{156}$ In the Sudarsky series, ${ }^{120}$ all subjects also had peripheral neuropathy, and alcohol was presumed to be a causative factor in half of the group, while the majority of the Fuh $^{121}$ cerebellar disorders were presumed to be idiopathic.

\section{Otber Causes}

The pattern of diagnoses in the primary care series ${ }^{122}$ is clearly different from that of the two neurological referral series $^{120,121}$ (see Table 1). Arthritis and orthostatic hypotension are the most common primary diagnoses, with multiple additional diagnoses such as postorthopedic surgery. ${ }^{122}$ Other common contributing, nonprimary diagnoses include acquired deformities, chronic lower extremity edema, and cataracts. ${ }^{122}$ Other causes of gait disorders identified in a later review ${ }^{135}$ included uremic and hepatic encephalopathy, CNS tumor or subdural hematoma, and depression. Medications are also important causes and include sedating psychotropic medications such as benzodiazepines, tricyclic antidepressants, and phenothiazines, ${ }^{135}$ as well as anticonvulsants (particularly phenytoin) and salicylates (in chronic intoxication). ${ }^{157}$

In case studies, older adults may present with reversible gait disorders attributable to clinically overt hypo- or hyperthyroidism. Ataxia with unsteady, staggering wide-based gait and other cerebellar signs is reportedly caused by hypothyroidism, ${ }^{158,159}$ although the cerebellar degeneration may relate to other accompanying conditions such as alcoholism. ${ }^{160}$ A sensory polyneuropathy related to hypothyroidism, while usually mild, ${ }^{161}$ may lead to ataxic gait. ${ }^{162,163} \mathrm{~A}$ myopathy may present with proximal weakness and myalgias ${ }^{164}$ but is uncommon in some series. ${ }^{16.5}$ (See Nickel ${ }^{166}$ for a more detailed discussion). Hyperthyroidism-associated cases of gait disturbances secondary to proximal myopathy may be most common ${ }^{167}$ although a related myelopathy and neuropathy have been reported. ${ }^{168-170}$ 
Table 2. Gait Characteristics of "Senile" Gait Disorder Group

\begin{tabular}{lc}
\hline \multicolumn{1}{c}{ Characteristic } & $\begin{array}{c}\text { No. Patients } \\
\text { (\% of group) }\end{array}$ \\
\hline Unable to perform tandem gait & $16(100)$ \\
Wide-based gait & $14(88)$ \\
Poor truncal stability & $12(75)$ \\
Gait dysrhythmia & $11(69)$ \\
Flexed attitude & $10(63)$ \\
Shortened steps & $10(63)$ \\
Bradykinesia & $8(50)$ \\
Loss of associated arm movement & $5(31)$ \\
Diminished ability to advance steps & $4(25)$ \\
Gait apraxia & $2(13)$ \\
Narrow base & $1(6)$ \\
\hline
\end{tabular}

From Koller et al. ${ }^{172}$

\section{Multiple Diseases and Other Contributing Clinical Features}

Although a single diagnosis can be determined in $56 \%$ of Sudarsky's series, ${ }^{120}$ a sizeable number, $28 \%$, have evidence of multiple diagnoses contributing to the gait disorder. In the primary care series, ${ }^{122}$ a larger percentage of subjects, $75 \%$, present with multiple diagnoses believed to contribute to the gait disorder. Multiple diagnoses may be problematic when common diseases such as arthritis overshadow rarer, potentially treatable coexisting diseases such as NPH. ${ }^{139}$

Additional factors may contribute to the gait abnormalities in the series noted above. In the Sudarsky series, ${ }^{120} 22 \%$ had dementia, which by itself may alter gait speed, ${ }^{92} 32 \%$ had symptoms such as dizziness, which might be attributed to vestibular disorders, and $50 \%$ had absent ankle reflexes and other signs of neuropathy. With the high rate of arthritis noted, most of Hough's ${ }^{122}$ patients considered pain to be the primary cause of their walking difficulties. Finally, $46 \%$ of Sudarsky's group ${ }^{120}$ complained of a fear of falling.

\section{"Senile" Gait Disorder}

Gait disorders are not an inevitable result of aging. Among noninstitutionalized older people aged 88 and older, $18 \%$ report no specific disease-related cause of gait impairment and on clinical exam apparently have no gait abnormality, including many with no difficulty in performing tandem gait. ${ }^{118}$ Nevertheless, when an older adult patient presents with a gait disorder but no accompanying clinical abnormalities, some suggest a diagnosis of "idiopathic senile gait disorder." ${ }^{110}$ Based on Critchley's description, ${ }^{171}$ Koller et al. ${ }^{172}$ operationalized this gait pattern as broad-based with small steps, diminished arm swing, stooped posture, flexion of the hips and knees, uncertainty and stiffness in turning, occasional difficulty initiating steps, and a tendency toward falling. In a series of 16 subjects with an abnormal gait pattern and no apparent clinical etiology, ${ }^{172}$ Table 2 shows the percentage of patients exhibiting a particular gait abnormality. Patients with this gait disorder walk less than half as fast as healthy older adults, have shorter stride lengths, have an increased percent of stride in total (particularly double) support, and have abnormal foot-floor contact and clearance. ${ }^{10,173}$ Many of these patients appear to be apprehensive or fearful during walking (particularly during transitional phases) and are more likely to have a history of falls and use walking aids. ${ }^{10,174}$ Fourteen percent of Sudarsky's patients ${ }^{120}$ exhibited this idiopathic gait disorder. These patients apparently had little or no spasticity, cerebellar ataxia, extrapyramidal rigidity, proprioception impairment (based on normal Romberg testing), or evidence of dementia.

Although the gait patterns in "senile gait disorder" are similar to those found in other diseases, the clinical findings are generally nonspecific and/or insufficient to identify another etiology. Despite the stooped posture and loss of arm movement, the clinical abnormalities are insufficient to make a diagnosis of parkinsonism. Some exhibit wide-based stance and truncal instability but show no CT evidence of cerebellar vermis atrophy or degeneration. Some of the gait patterns are consistent with those found in NPH, and although some ventriculomegaly is associated with the gait disorder, few subjects meet the clinical or radiological criteria for NPH. Sabin ${ }^{175}$ discusses the evidence for and against the possibility that "senile gait disorder" may be a manifestation of subtle extrapyramidal, pyramidal, frontal lobe, or peripheral nerve disease. Perhaps gait abnormalities not explainable by overt signs and symptoms of clinical disease are the result of white matter hypodensity on head CT. ${ }^{128}$ Perhaps this is an early stage of a progressive gait disorder that acts as a precursor to an as-yet-asymptomatic disease. ${ }^{118}$ Perhaps the presence of a cognitive disorder contributes to the gait abnormalities seen with "senile gait disorder," ${ }^{174}$ given that at least half of the Koller ${ }^{172}$ patients were demented. Nearly all of the "senile gait disorder" patients in the Elble ${ }^{173}$ series were at least mildly demented and many were ultimately diagnosed as having Alzheimer's disease, vascular dementia, or normal pressure hydrocephalus. Some argue that many gait disorders in older adults, including "senile gait disorder," appear similar, regardless of disease etiology, because the gait characteristics are influenced heavily by reductions in stride length. ${ }^{17.3}$ The term "senile gait disorder," thus, does not refer to a well defined, homogeneous disorder and is not useful in labeling gait in older adults.

\section{Psychogenic Gait Disorders}

These disorders are common in adults aged 30 to 50 but have been known to occur beyond age $70 .{ }^{76,177}$ Examples include "astasia-abasia," when the patient is unable to stand (astasia) or walk (abasia) despite normal leg function while supine, and "camptocormia," exaggerated trunk flexion while walking. ${ }^{178}$ Psychogenic gait disorder patients have an inconsistent but generally normal examination and may either display a dramatic resolution of symptoms or show no further organic explanation on long-term follow-up. ${ }^{177,179}$ Exaggerated ataxic movements occur commonly, usually without falling, and include exaggerated swaying, which may increase over time, sudden knee buckling, staggering long distances to obtain support, attempting to grab and pull down the observer, classic tightrope balancing, uneconomic postures which waste muscular energy, small cautious steps with fixed ankle joints ("walking on ice"), excessive slowness or hesitation, and momentary stance and gait fluctuations, often in response to suggestion and improved by distraction. ${ }^{177,179}$

\section{A CLASSIFICATION SCHEME FOR GAIT DISORDERS}

Based on a scheme developed by Nutt, ${ }^{143}$ gait disorders can be divided into predominately low, middle, and high sensorimotor levels (see Figure 4). Note that these levels are 


\section{Sensorimotor Level Description/Examples}

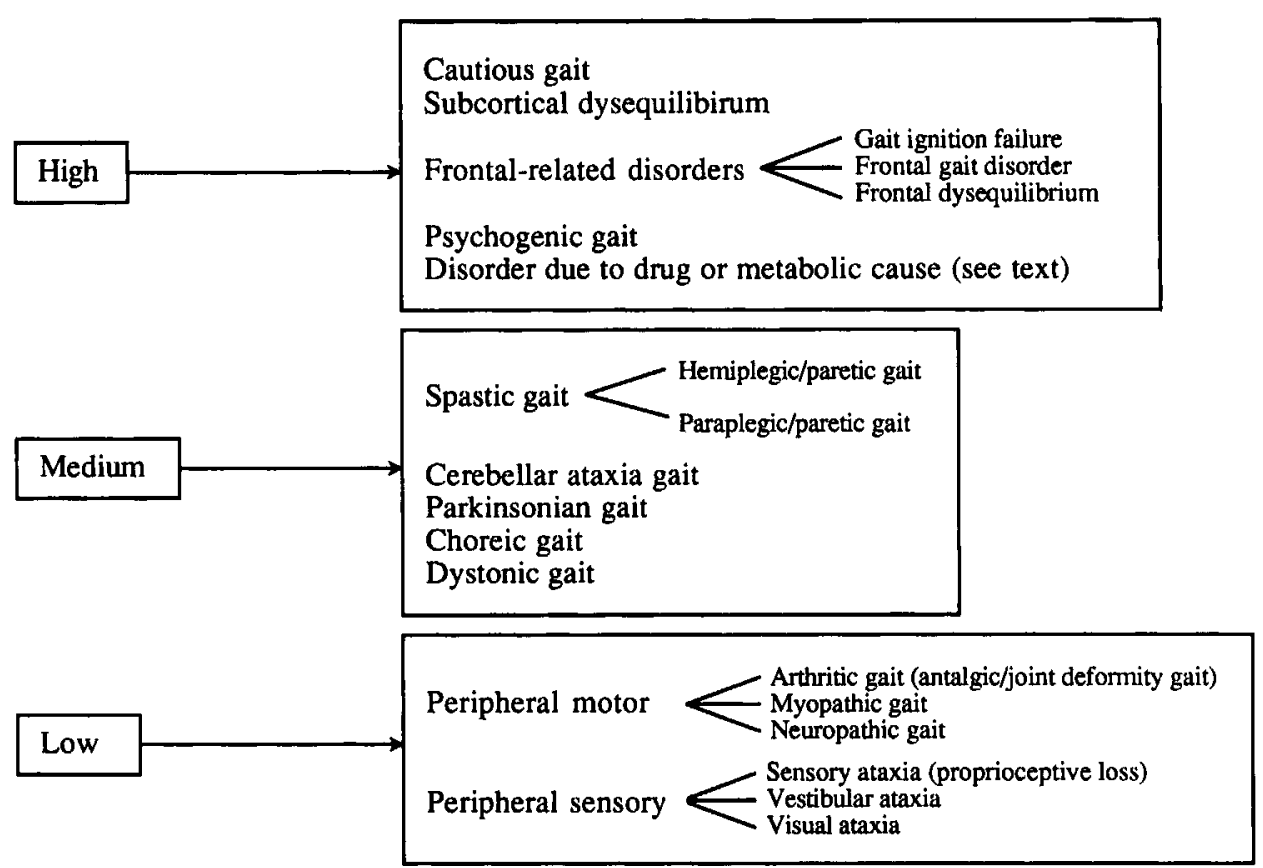

Figure 4. Gait disorder classification scheme for older adults (adapted from Nutt ${ }^{143}$ ).

not based exclusively on anatomy because some disorders involve multiple levels, e.g., subcortical lesions occur in predominately cortical disorders and vice versa (e.g., Parkinson's disease). ${ }^{180}$ Drug and metabolic etiologies may also overlap levels, even though the primary effect may be on the high sensorimotor level (e.g., phenothiazines, high sensorimotor level attributable to sedation and anticholinergic effect, middle sensorimotor level attributable to extrapyramidal effect).

At the lowest level are disorders of proprioceptive, vestibular, visual, and musculoskeletal function that are often distal to the central nervous system. Loss of proprioception, either from peripheral nerve or posterior column deficit, leads to unsteady, uncoordinated (ataxic) gait. Loss of vestibular function leads to unsteady, and perhaps weaving or "drunken" gait. Patients with visual loss are more tentative and uncertain than ataxic. Pelvic girdle weakness can produce exaggerated lumbar lordosis and lateral trunk flexion ("waddling" and "Trendelenberg" gait) and difficulty in rising from chairs and negotiating stairs. Proximal motor neuropathies may also lead to "waddling" or an exaggerated foot contact with the floor ("foot slap"). In the distal neuropathies, distal weakness (particularly of the ankle dorsiflexors, ie, "foot drop") leads to exaggerated hip flexion and lifting of the foot ("steppage gait") followed by a "foot slap". Disorders of the musculoskeletal system are elaborated upon elsewhere. ${ }^{181,182}$ In antalgic gait, patients avoid weight-bearing on the affected area and shorten the stance phase. The trunk shifts over the affected side with hip pain. The painful knee is often flexed, while spinal pain causes slow, short steps, avoidance of heel strike, and decreased lumbar lordosis. Feet that are deformed and painful with weight bearing alter gait. ${ }^{183}$ Nonantalgic features of arthritis that cause gait abnormalities, particularly at the knee, include contractures, deformity-limited motion, and buckling with weight-bearing. Kyphosis and ankylosing spondylosis can mimic the stooped parkinsonian posture. Leg length inequalities may also cause trunk and pelvic motion abnormalities. Patients with these disorders can generally compensate and maintain independent ambulation if their cognition and central nervous system is intact.

At the middle level, the central nervous system selects postural and locomotor responses, but the execution is faulty and there are disruptions in the motor and sensory modulation of gait. Gait is initiated without difficulty but the stepping pattern is abnormal. The most common classically defined disturbances are spastic gait, particularly related to corticospinal tract damage, and parkinsonian gait. In spastic hemiparesis, such as from a stroke, the leg is swung in a semi-circle from the hip with the pelvis tilted up ("circumduction") and the hip adducted. The knee may hyperextend ("genu recurvatum") with lack of flexion and the ankle excessively plantar flexes and may invert ("equinovarus"). The arm, when involved, may be held flexed and adducted with minimal swing. With less paresis, some may only lose the arm swing and drag or scrape the foot. In spastic paraparesis, such as in cervical spondylosis, both legs circumduct, steps are short, shuffling, and scraping, and, when severe, the hip adducts so that the knees cross in front of each other ("scissoring"). Characteristic features of parkinsonian gait include small, shuffling steps, hesitation, festination (acceleration), propulsion (falling forward when walking), retropulsion (falling backward), turning en bloc (moves whole body when turns), and absent arm swing. Of note, other neurological syndromes such as Shy-Drager syndrome, olivopontocerebellar degeneration, and progressive supranuclear palsy have parkinsonian gait features as well as other associated symptoms and signs, such as multiple system atrophy. In cerebellar ataxia, the wide-based gait is accompanied by increased trunk sway and irregular timing and amplitude of steps, particularly on turns. 
At the highest level, categorization is confusing, mainly because the gait characteristics can be nonspecific, are caused by a number of disease entities, and may have subcortical in addition to cortical features. Alterations in cognitive integration and processing, and behavioral aspects such as fear are often present (hence the inclusion of psychogenic gait at this lcvel). Nutt ${ }^{14.3}$ provides five separate classifications (see Figure 4) but these too, may be overlapping, or, as with cautious gait, may be superimposed on other diseases. Cautious gait, which suggests the presence of fear of falling, is characterized by normal to widened base, shortened stride, decreased velocity, and en bloc turns. Most patients are aware of a balance disorder, have appropriate postural responses, and are appropriately cautious, responding to a real or perceived sense of instability. In subcortical disequilibrium, locomotion is impaired because patients exhibit inappropriate postural responses, to such an extent that the patient may be unable to stand or exhibit protective fall responses. Ocular palsies, dysarthria, and extrapyramidal signs may be associated, and the onset may be sudden, as in an acute vascular event, or slow, such as might be seen in multi-infarct-related progressive supranuclear palsy. ${ }^{184}$ If able to walk, patients can have appropriate stepping rhythm and direction. Difficulty standing and a tendency to fall without an appropriate fall response, despite generally preserved strength and sensation, is analogous to that reported after acute vascular unilateral lesions of the thalamus, ${ }^{185}$ putamen, ${ }^{186}$ and midbrain. ${ }^{187}$

The last three disorders, gait ignition failure, frontal gait disorder, and frontal disequlibrium, may be part of the same disease etiology, namely cerebrovascular disease and/or $\mathrm{NPH}$, and consequently may have similar features. A glossary (see Appendix) contains a number of terms used to describe these types of disorders, particularly in regard to thcir relationship to gait apraxia. The gait disorders characterized by these terms are also overlapping, and many likely relate to underlying cerebrovascular disease, such as "arteriosclerotic-", "lower-half-", and "lower body-parkinsonism."136,188 In gait ignition failure, there is marked difficulty in initiating gait and maintaining locomotion in the absence of impaired cquilibrium, cognition, limb praxis, or parkinsonism. Steps are short and shuffling and decrease as walking continues. Diversion of the patient's attention, negotiating narrow passages, or turning commonly precipitate freezing and resumption of shuffling. In frontal gait disorder, the gait pattern is characterized by a variable base (narrow to wide), short steps, shuffling, start and turn hesitation, and some disequilibrium. Patients with frontal gait disorder, are more likely than those with advanced Parkinson's disease (and other akinetic-rigid syndromes) to exhibit a wider base, an upright posture, and preservation of arm swing. The accompanying cerebrovascular disease can produce cognitive lesions, pseudobulbar palsy with dysarthria, frontal release signs, paratonia, pyramidal signs and urinary disturbances. In frontal dysequilibrium, such as from a frontal mass lesion, the postural responses worsen so that patients cannot stand unsupported and cannot organize trunk and leg movements to rise from a seated position or walk.

\section{GAIT DISORDER EVALUATION}

A gait evaluation usually involves (1) describing the extent to which disabled gait differs from able-bodied gait, (2) identifying the mechanisms responsible for the gait disorder, and (3) determining the effect of an intervention on gait performance (based on Craik ${ }^{56}$ ). Ultimately, the value of gait assessments, particularly on a "high-tech" level, may be in the identification of pathological mechanisms underlying performance. Use of standard clinical and radiologial methods to evaluate a gait disorder parallels the evaluation of fall risk (see $\mathrm{King}^{189}$ ) and the evaluation for underlying neurological disease recommended by Sudarsky. ${ }^{120,13.5}$ Note that agespecific guidelines, and sensitivity, specificity, and costeffectiveness of these work-ups remain to be determined. A discussion of the various methods of gait assessment follows below.

\section{Simple Observational Evaluation}

Clinician observation of the type, extent, and temporal nature of a gait disorder tends to be subjective, generally qualitative, and only moderately reliable.$^{56,190,191}$ Functional approaches document the use of assistive devices, the degree of human assistance (either manual or verbal), the distance the patient can walk, and the types of surfaces the patient can negotiate, the Functional Ambulation Classification ${ }^{192,193}$ (see Table 3). Timed versions of these measures, such as walking in parallel bars or walking with a cane, are reliable in patients with mild neurological deficits. ${ }^{194,195}$ Functionbased balance and gait evaluations have also been proposed ${ }^{19,143,189}$ (see Table 4). Others propose extending the functional evaluation to include other conditions that the patient might encounter, such as stairs and ramps. ${ }^{56}$

\section{Instrumented Evaluation}

Instrumented methods used to acquire gait performance data vary in terms of cost, time, personnel and technical expertise, and equipment required. Relatively simple techniques that yield temporal distance information (such as velocity and step length) range from use of a stop watch (which may introduce observer effects) to presumably less obtrusive measures such as optical beams, ${ }^{196,197}$ ultrasonic pulses, ${ }^{198}$ grid-patterned or instrumented walkways, ${ }^{199-201}$ ink footprints $192,193,202$, and a lightweight, instrumented trolley attached to the patient's heels. ${ }^{203}$ Time-distance parameters, particularly velocity and stride length, appear reliable and correlate with clinical measures such as reduction of dependency on a therapist or assistive device. ${ }^{204,205}$

Other techniques acquire kinematic (i.e., body motion) data by the use of photographic, optoelectronic, or, in some cases, accelerometric instruments. ${ }^{206,207}$ Some attempt to determine a set of movements that are the key predictors of gait, namely pelvic rotation, pelvic tilt, knee (and hip) flexion in the stance phase, foot-ankle-knee rotation interactions, and lateral pelvic displacement. ${ }^{208,209}$ Alterations in shoulder extension, arm-heel strike asynchrony, and guardedness can differentiate nursing home fallers from controls. ${ }^{111}$ Clinician visual rating of abnormal gait kinematics has been proposed for hemiplegia. ${ }^{210}$ Others review the advantages and disadvantages of the various kinematic data acquisition techniques, pointing out that instrumentation may interfere with natural gait, that the field of view and accuracy of data acquisition may be limited, and that data reduction may be problematic. $^{56,211,212}$

Analyses of gait kinetics, namely the forces associated with movement, particularly as measured on a floor force plate, can estimatc weakness and compensatory postures ${ }^{213}$ but have some of the same limitations as the kinematic techniques. ${ }^{182,211,214}$ Instrumented footwear are used to measure temporal aspects of 
Table 3. Functional Ambulation Classification

Category

0 Nonfunctional Ambulation

1 Ambulator-Dependent: Physical Assistance Level II

2 Ambulator-Dependent: Physical Assistance Level I

3 Ambulator-Dependent: Supervision

4 Ambulatory-Independent: Level Surfaces Only

5 Ambulator-Independent
Definition

Cannot ambulate, ambulates in parallel bars only, or requires supervision or physical assistance from more than one person to ambulate safely outside of parallel bars.

Requires manual contacts of no more than one person during ambulation on level surfaces. Manual contacts are continuous and necessary to support body weight as well as maintain balance and/or assist coordination.

Requires manual contact of no more than one person during ambulation on level surfaces. Manual contact consists of continuous or intermittent light touch to assist balance or coordination.

Physically ambulates on level surfaces without manual contact of another person but for safety requires standby guarding of no more than one person because of poor judgment, questionable cardiac status, or the need for verbal cuing to complete the task.

Ambulates independently on level surfaces but requires supervision or physical assistance to negotiate any of the following: stairs, inclines, or nonlevel surfaces.

Ambulates independently on nonlevel and level surfaces, stairs, and inclines.

From: Holden ${ }^{192}$ (reprinted with permission).

gait $^{215,216}$ and estimate activity level. ${ }^{217}$ Other techniques include gait energetics, i.e., the estimation of the energy expenditure encountered during walking on a treadmill or walkway. ${ }^{33,182,211,214,218}$ More feasible, yet crude, estimates of energy expenditure include changes in heart rate. Waters ${ }^{219}$ and Perry ${ }^{182}$ reviewed the energy expenditure of gait disorders in various diseases and how treatment and assistive device use can improve walking efficiency (decrease energy requirements). Finally, electromyography (EMG) is used to determine the timing and intensity of muscle activation during gait. ${ }^{182,211,214}$ Errors in timing, such as premature or prolonged muscle activation, and intensity, such as when the muscle intensity is excessive, may be useful in understanding a gait disorder. ${ }^{56}$ When kinematics, kinetics, and EMG are combined and/or computer modeled, one can investigate the mechanisms underlying the motor patterns observed and the control of posture and balance while walking either without ${ }^{220,221}$ or with an assistive device. ${ }^{207,222-224}$ The modeling studies may have diagnostic value, whereas the standard kinematic, temporal, and distance measures may be useful in monitoring patient progress. ${ }^{22.5}$

The challenge is to utilize in a clinically relevant way the vast number and sophistication of instrumented measures available. Considering the time and expense involved, are any of these techniques more clinically useful than simple observational or speed data? How important clinically is a more precise yet small improvement, for example, in gait speed (e.g., 1.0 to $1.1 \mathrm{~m} / \mathrm{s}$ )?

\section{GAIT DISORDER TREATMENT AND REHABILITATION}

Many of the reports dealing with treatment and rehabilitation of gait disorders in older adults are retrospective chart reviews and case studies. Approximately one-quarter of the neurological referral series ${ }^{120,121}$ cite conditions for which primary treatment, either medical or surgical, is available. These conditions include previously unrecognized Parkinson's disease, metabolic disturbances, intracranial tumors, $\mathrm{NPH}$, myelopathy due to compression, inflammatory polyneuropathy, and depression. Neither series gives quantitative follow-up, although progression occurs in those with no treatable disorder, often requiring institutionalization. ${ }^{120}$

What constitutes improvement in gait? Although the aesthetic appearance of a patient's gait may be "abnormal" and/or demonstrate residual disability, other clinical parameters, such as reduction in weight-bearing pain, suggest functional improvement. Thus, outcome variables other than standard gait measures are also important. Achievement of premorbid gait patterns may be unrealistic, and improvement in measures such as gait speed is a reasonable goal as long as gait remains safe.

\section{Medical and Physical Therapy Interventions}

A number of disease-related gait disorders respond to pharmacological therapy, but many patients are left with residual disorders. Case reports suggest that gait disorders are responsive to folate ${ }^{154}$ and $B_{12}$ repletion therapy ${ }^{226,227}$; 
Table 4. Items in Functional Assessment of Balance and Gait

\begin{tabular}{|c|c|}
\hline From Tinetti ${ }^{119}$ & From Nutt 143 \\
\hline \multicolumn{2}{|l|}{ Balance } \\
\hline \multicolumn{2}{|l|}{ Sitting balance } \\
\hline \multicolumn{2}{|l|}{ Immediate standing balance } \\
\hline \multicolumn{2}{|l|}{ (feet close together) } \\
\hline Turning balance $(360 \mathrm{deg})$ & Negotiation of turns \\
\hline Nudge on sternum & $\begin{array}{l}\text { Withstand push fore/aft, } \\
\text { side-to-side with } \\
\text { effective responses }\end{array}$ \\
\hline \multicolumn{2}{|l|}{ Neck turning } \\
\hline \multicolumn{2}{|l|}{ One leg standing balance } \\
\hline \multicolumn{2}{|l|}{ Reaching up } \\
\hline \multicolumn{2}{|l|}{ Bending down } \\
\hline \multicolumn{2}{|l|}{ Sitting down } \\
\hline & $\begin{array}{l}\text { Effective response if } \\
\text { spontaneous loss of } \\
\text { balance }\end{array}$ \\
\hline \multicolumn{2}{|l|}{ Gait } \\
\hline Initiation of gait & Gait initiation, hesitation \\
\hline Step height & Foot clearance \\
\hline Step length & Stride length \\
\hline Step symmetry & Cadence \\
\hline Step continuity & Freezing \\
\hline \multicolumn{2}{|l|}{ Path deviation } \\
\hline \multicolumn{2}{|l|}{ Trunk stability } \\
\hline \multicolumn{2}{|l|}{ Walk stance } \\
\hline \multirow[t]{3}{*}{ Turning while walking } & Hesitation while turning \\
\hline & Width of base \\
\hline & Arm swing \\
\hline
\end{tabular}

however, larger series of $\mathrm{B}_{12}$ deficiency treatment indicate that ataxia and abnormal gait resolve completely in more than half of patients but only partially in the rest. ${ }^{151,153}$ Folate treatment in older patients with low serum folate levels and no apparent other etiology for myelopathy is successful in achieving ambulatory status in six of ten patients who have been chair-or bed-bound previously. ${ }^{155}$ Lowered responsiveness to therapy may be attributable to more severe and long standing deficits, ${ }^{151}$ a multifactorial gait disorder ${ }^{228}$ with concurrent diseases such as alcoholism or malignancy, ${ }^{229,230}$ a myelopathic (vs neuropathic) component, ${ }^{150}$ and perhaps age greater than $70 .^{150}$ In regard to thyroid disease, all 24 cases with overt clinical manifestations of hypothyroidism had reductions in their associated unsteadiness and ataxic gait after thyroid replacement. ${ }^{158}$ The treatment response of the gait disorder related to hypothyroid sensory neuropathy ranged from complete resolution within 8 months to continued residual manifestations after 1 year. ${ }^{162,163}$ Hyperthyroidism-associated gait disorders may also resolve after antithyroid treatment. ${ }^{168-170}$ In Parkinson's disease, acute administration of L-Dopa improves gait velocity ${ }^{231}$ by as much as $38 \%$ over baseline. ${ }^{232}$ Patients with knee osteoarthritis given nonsteroidal medications such as piroxicam ${ }^{233}$ or naproxen ${ }^{234}$ show improvement in gait speed (by $16-$ $18 \%$ ) and stride length (by $9 \%$ ), as well as in other gait measures. In response to immunological agents such as prednisone, five patients (mean age 70) with high serum IgM, a predominantly sensory peripheral neuropathy, and a small step, wide-based gait with difficulty in turning became less dependent on an assistive device or were better able to perform tandem gait. ${ }^{235}$

Gait improves with physical therapy, although the improvements may be modest, and residual disability is frequent. Parkinson's patients undergoing physical therapy improve in their rigidity and bradykinesia, ${ }^{236}$ although the effect may be insignificant. ${ }^{237}$ In response to exercises ranging from stretching to karate training, gait speed improvements up to $25 \%$ may occur in Parkinson's patients over a 3 to 4-month period, primarily in patients with less severe baseline symptoms. ${ }^{238,239}$ Using visual cues such as a cane handle placed on the ground ${ }^{240}$ helps these patients improve stride length and decrease double support duration. ${ }^{241,242}$ Knee osteoarthritis patients participating in controlled 8-week trials of supervised walking, stretching, strengthening, and patient education increase their gait speed and stride length by 9 to $18 \% .{ }^{243,244}$ Other 12 to 16 -week programs using standard physical therapy, ${ }^{245}$ aerobic walking, or aquatic exercises ${ }^{246}$ decrease 50 -foot walk time by approximately $10 \%$. Finally, modest improvement with residual disability is a common theme for stroke patients. Of 60 survivors admitted for an acute stroke and given therapy, ${ }^{247,248} 15(25 \%)$ were unable to walk and $14(23 \%)$ walked independently at both initial and final assessment. Of the 30 showing substantial recovery, 10 regained 'normal' speed and eight remain dependent on an assistive device. Of 19 patients followed up 1 to 5 months later, approximately one-third increased gait speed slightly (0.1-0.7 m/sec), one-third did not change, and one-third worsened slightly. Maximal walking improvement is reached in $95 \%$ of patients by 11 weeks. ${ }^{249}$ Physical therapy given 3 months to 1 year post-stroke results in modest $(8-9 \%)$ gait speed improvement ${ }^{250,251}$ compared with slowing (by $12 \%$ ) in untreated controls.

\section{Cervical Myelopatby and Lumbar Stenosis}

Few controlled prospective studies and virtually no randomized studies address the outcome of surgical treatment for compressive cervical myelopathy or lumbar stenosis. A number of problems plague the available series: outcomes such as pain and walking disability are not reported separately; the source of the outcome rating is not clearly identified or blinded; the criteria for classifying outcomes differ; the follow-up intervals are variable; and the selection factors for conservative versus surgical treatment between studies differ or are unspecified..$^{252-255}$ Most of the outcome percentages below include all ages, although the mean age in many surgical series is usually greater than 60 years old.

Most of the patients aged 60 or older with symptomatic cervical spondylotic myelopathy and/or radiculopathy have at least minimal postoperative improvement in symptoms, signs, and/or ADL dependency ${ }^{256,257}$ and apparently respond as well as a younger cohort. ${ }^{258}$ In a meta-analysis of older studies, Epstein ${ }^{259}$ noted overall clinical improvement (not just in gait) ranging from $57 \%$ to $85 \%$ in 1241 patients operated on for cervical spondylotic myelopathy. Other studies suggest more modest improvements. Of 55 patients followed up for a mean of more than 7 years, $35 \%$ improved in 
their self-reported distance walking and maintained their improvement, and $44 \%$ were worse at follow-up. ${ }^{260}$ Twenty percent of patients showed improvement during the initial 2 years after the operation, stabilized for a period ranging from 1 month to 18 years, and then worsened as a result of progressive stiffness and weakness. Better outcomes occur in those who do not have coexisting chronic disease (such as emphysema) and who are not yet dependent on a walker or human assistance. ${ }^{261}$ With conservative, nonsurgical treatment (such as with a cervical collar), periods without new or worsening symptoms as well as spontaneous improvement may occur, ${ }^{262}$ although older adults (over age 60) may not fare as well. ${ }^{258}$ In patients with more severe, long-standing disabilities (e.g., more than than 2 years), both conservative and surgical measures may yield improvement in only 30 to $50 \%$ of patients. ${ }^{252,263}$

Recent meta-analyses of laminectomy for lumbar stenosis and fusion for a variety of disorders, including stenosis, find nearly $70 \%$ of patients with at least satisfactory outcomes, with wide interstudy variation in these percentages. $^{253,254}$ The majority of studies found no outcome differences with increasing age, even with patients up to age $87,,^{264-268}$ although patients with concurrent diseases such as cardiopulmonary disease had a poorer outcome. ${ }^{269,270}$ In studies with 4 to 5 -year follow-up postlaminectomy, from 57 to $84 \%$ of patients reported positive results, ${ }^{268,269,271}$ particularly in pain reduction, ${ }^{269}$ and in the mean walking distance where pseudoclaudication develops. ${ }^{271}$ Nevertheless, residual disability was common: $77 \%$ had walking limitations attributed to residual lower back or leg symptoms, ${ }^{268} 46 \%$ were unable to walk at least 2 blocks, and $21 \%$ were unable to walk 15 meters. ${ }^{269}$ Surgery may be avoidable or postponed without severe functional deterioration in symptomatic patients. In a small series of patients $(n=19)$ with neurogenic claudication and relatively mild walking disability who were followed up for a mean of 31 months without surgery, subjective assessment of walking capacity improved in $42 \%$, was unchanged in $32 \%$, and worsened in $26 \%{ }^{272}$

\section{Normal Pressure Hydrocephalus}

Studies of the responses of patients with normal pressure hydrocephalus (NPH) to ventriculo-peritoneal or -atrial shunting also tend not to be prospective or controlled and tend to have problems with outcome assessment and followup. Biases exist in regard to patient selection (only patients in whom shunt-responsive NPH was probable were operated on) and publication (only positive results were published). ${ }^{140}$ In a review of shunting studies for $\mathrm{NPH}$, overall improvement in function may be more striking in recent studies (studies from 1977 to 1989 versus 1966 to 1976 ) and occurs in nearly $75 \%$ of patients, with marked improvement in just over $50 \% .{ }^{140}$ However, there is a wide range of improvement, depending on patient selection and the degree and duration of improvement. Prolonged improvement may be maintained in only $15-20 \%$ of patients with NPH. ${ }^{140}$ Factors associated with more positive outcomes with shunting include (1) a diagnosis of secondary NPH versus idiopathic NPH and ${ }^{140}$ (2) the presence of either gait disturbance alone or in combination with dementia and incontinence, particularly when the gait disturbance occurs before the onset of dementia. ${ }^{142,144,273,274}$ CT findings such as small cortical sulci and large ventricles have been proposed to predict a positive response to shunting by some $e^{142,275}$ but not others. ${ }^{7,276}$
Some propose invasive preoperative predictors of improvement post-shunting, to include: (1) the presence of high amplitude waves on intracranial pressure monitoring ${ }^{277}$; the ratio of ventricular versus overall total intracranial isotope activity, using quantitative cisternography ${ }^{278}$; the clinical response to serial removal of spinal fluid ${ }^{279-281}$; and resorption of cerebrospinal fluid, as measured by the conductance to outflow of CSF as measured by lumboventricular perfusion. ${ }^{275}$

\section{Subdural Hematoma}

Despite similar methodological problems in these series, surgical removal of a chronic subdural hematoma results in marked improvement in unsteady gait and mental status. ${ }^{282-284}$ Surgical treatment of CT-diagnosed chronic subdural hematoma results in full recovery without deficit in $80 \%$ of patients, including reversal of hemiplegia and drowsiness (which might lead to a gait disorder). ${ }^{285}$

\section{Leg Osteoarthritis}

Patients who undergo total knee replacement for osteoarthritis can expect gains in gait velocity and stride length, on average, up to $37 \%$, as well as gains in joint range and speed of motion, although to a level still markedly below that of healthy controls. ${ }^{286-288}$ When the disease occurs only unilaterally and there are no other associated medical conditions, gait measures approach the lower limit of normal by 1 to 3 years postoperation. ${ }^{289,290}$ Gait abnormalities persist in these patients for a number of reasons, including maintenance of the preoperative gait pattern, deformity/involvement of the contralateral side, continued pain, continued abnormal muscle strength and coordination (as evidenced by abnormal flexion-extension knee moments), and partial loss of proprioceptive control at the knee $287,288,291$.

Similar relationships exist after hip replacement for osteoarthritis. Walking distance increases, ${ }^{292,293}$ and gait velocity and step length may improve by up to $100 \%$ at 6 months postoperation (with maintenance of improvements by 4 years postoperation). ${ }^{294,295} \mathrm{Up}$ to $58 \%$ of these patients use no assistive device at 6 months postoperation ( $88 \%$ by 4 years). Despite these improvements, patients may still have pain, "limp," and/or limited walking ability, ${ }^{292,293}$ and gait velocity and hip motion are still below standard norms at 6 months postoperation. ${ }^{296}$ Two years postoperatively, even in patients with near normal gait velocity, reductions are seen in single limb stance duration and hip motion, abnormal hip muscle EMG patterns are still present, and less force is applied through the operated limb, suggesting persistent leg weakness. ${ }^{297}$ Gait findings such as these may be attributable to continued postoperative pain and reliance on an assistive device. $^{298}$

\section{Use of Assistive Devices}

More than $23 \%$ of noninstitutionalized older adults aged 75 and older use a mobility technology device, with $49 \%$ using a cane (walking stick), $24 \%$ using a walker, and $12 \%$ a wheelchair. ${ }^{299}$ Unfortunately, up to $70 \%$ of patients use canes that are faulty, damaged, or are not at the appropriate height. ${ }^{300,301}$ Placement of the cane in the contralateral hand may be useful in relieving ipsilateral hip pain ${ }^{302}$ and in maintaining a reciprocal stepping pattern. ${ }^{303}$ However, ipsilateral cane use can also help in reducing the force acting on the hip ${ }^{304}$ and the muscle activity around the knee ${ }^{305}$ Other 
work suggests that there is no relationship between appropriate cane hand or length and subsequent confidence in performing activities, functional ability, or falling. ${ }^{306}$ Furthermore, contrary to the common belief that older adults do not view assistive device use positively, among older adults who travel independently to a shopping center, cane use is associated with improvements in confidence and self-reported functional ability. ${ }^{306}$ Clearly, the relationships between patient preferences and abilities, the home environment, and device characteristics is complex. ${ }^{307,308}$

\section{SUMMARY AND CONCLUSIONS}

Difficulty in walking is common in older adults and can be a predictor of overall functional status. Measures of gait such as speed decline with age, but the decline is small in healthy older adults less than age 70 . Factors ranging from anthropometry to cognition affect gait, and the effect of exercise is apparently modest. A number of diseases, often in combination, cause gait disorders. The categorization of these disorders becomes difficult when higher order cortical changes occur, particularly in response to cerebrovascular disease. There are few standard methods of gait disorder evaluation, other than standard clinical and radiological measures, and few data documenting the cost-effectiveness of these methods. Gait assessment ranges from simple observation to more sophisticated instrumented techniques, and yet evaluation of gait speed may be sufficient for most clinical purposes. Data on treatment and rehabilitation outcomes for gait disorders are frequently limited methodologically, particularly in the surgical literature. Gait improvements are modest, and residual disability and/or gait abnormalities are common. With new diagnostic technology and techniques available, as well as a new emphasis on cost-effectiveness, the evaluation and treatment of gait disorders in older adults will continue to evolve.

\section{ACKNOWLEDGMENTS}

The author thanks Laurie Katz, MD, Stella Gotts, Michael Felkey, Aarti Raheja, Cristen Stirrup, and Jessica Ulbrich for their assistance in manuscript preparation and library research. The author also thanks Dan Murman, MD, Albert Schultz, PhD, and James Ashton-Miller, PhD, for their insightful comments regarding the manuscript contents. The contributions and assistance of the residents and staff of Glacier Hills Retirement Center are also gratefully acknowledged.

\section{REFERENCES}

1. Dawson D, Hendershot G, Fulton J. Aging in the Eighties. Functional Limitations of Individuals Age 65 and (Over. Advance Data from Vital and Health Statistics. No. 133. (DHHS Pub. No. 87-1250). Hyattsville, MD: Public Health Service, Centers for Disease Control, 1987.

2. Leon J, Iair T. Functional Status of the Noninstitutionalized Elderly: Estimates of ADI, and IADI. Difficulties (DHHS Publication No. (PHS) 903462). National Medical Expenditure Survey Research Findings 4, Agency for Health Care Policy and Research. Rockville, MD: Public Health Service, 1990.

3. Cornoni-Huntley J, Brock DB, Ostfeld AM et al. Established Populations for Epidemiologic Studies of the Elderly: Resource Data Book. National Institutes of Health Publication No. 86-2443. Bethesda, MD: National institute on Aging, 1986.

4. Lair T, Lefkowitz D. Mental Health and Functional Status of Residents of Nursing and Personal Care Homes. (DHHS publication No. (PHS) 90-3470). National Medical Expenditure Survey Research Findings 7, Agency for Health Care Policy and Research, Rockville, MD: Public Health Service, 1990 .
5. Verbrugge LM, Lepkowski JM, Konkol L.L. Levels of disability among U.S. adults with arthritis. J Gerontol 1991;46(suppl):S71-83.

6. Guralnick JM, Ferrucci L, Simonsick EM et al. Lower-extremity function in persons over the age of 70 years as a predictor of subsequent disability. N Engl J Med 1995;3.32:556-561.

7. Cress ME, Schechtman KB, Mulrow CD et al. Relationship between physical performance and self-perceived physical function. J Am Geriatr Soc 1995;43:93-101.

8. Bradley JD, Brandt KD, Katz BP ct al. Comparison of an antiinflammatory dose of ibuprofen, an analgesic dose of ibuprofen, and acetaminophen in the treatment of patients with osteoarthritis of the knee. N Engl J Med 1991;325:87-91.

9. Spiegel JS, Paulus HE, Ward NB et al. What are we measuring? An examination of walk time and grip strength. J Rheumatol 1987;14:80-86.

10. Hoxie RE, Rubinstein LZ. Arc older pedestrians allowed enough time to cross intersections safely? J Am Geriatr Soc 1994;42:241-244.

11. Friedman PJ, Baskett JJ, Richmond DE. Cognitive impairment and its relationship to gait rehabilitation in the elderly. N Z Med J 1989;102:603606.

12. Friedman PJ, Richmond DE, Baskett JJ. A prospective trial of serial gait speed as a measure of rehabilitation in the elderly. Age Ageing $1988 ; 17: 227-235$.

13. Guyatt GH, Thompson PJ, Berman LB ct al. How should we measure function in patients with chronic heart and lung disease? J Chronic Dis $1985 ; 38: 517-524$

14. Butland RJA, Pang J, Gross ER et al. Two-, six-, and 12-minute walking tests in respiratory disease. Br Med J 1982;284:1607-1608.

15. Bittner V, Wciner DH, Yusuf $S$ et al. Prediction of mortality and morbidity with a six-minute walk test in patients with left ventricular dysfunction. JAMA 1993;270:1702-1707.

16. Lipkin DP, Scriven AJ, Crake $T$ et al. Six-minute walking test for assessing exercise capacity in chronic heart failure. $\mathrm{Br}$ Med J 1986;292:653-655.

17. Guyatr GH, Sullivan MJ, Thompson PJ et al. The 6-minute walk: A new measure of exercise capacity in parients with chronic heart failure. Can Med Assoc J 1985;132:919-923.

18. Cowley AJ, Fullwood LJ, Muller AF ct al. Exercise capability in heart failure: Is cardiac output important after all? I ancet 1991;337:771-773.

19. Cockcroft AE, Saunders MJ, Berry G. Randomised controlled trial of rehabilitation in chronic respiratory disability. Thorax 1981;36:200-203.

20. McGavin CR, Gupta SP, Lloyd EL et al. Physical rehabilitation for the chronic bronchitic: Results of a controlled trial of exercises in the home. Thorax 1977;32:307-311.

21. Sinclair DJM, Ingram CC. Controlled trial of supervised exercise training in chronic bronchitis. Br Med J 1980;280:519-521.

22. Leitch AG, Morgan A, Ellis DA et al. Effect of oral salbutamol and slowrelease aminophylline on exercise tolerance in chronic bronchitis. Thorax 1981;36:787-789.

23. Lake FR, Henderson $K$, Briffa $T$ et al. Upper-limb and lower-limb exercise training in paticnts with chronic airflow obstruction. Chest 1990;97:10771082.

24. Ries AI, Moser KM. Comparison of isocapnic hyperventilation and walking exercisc training at home in pulmonary rehabilitation. Chest 1986;90:285-289.

25. Vathenen AS, Britton JR, Ebden P et al. High-dose inhaled albuterol in severe chronic airflow limitation. Am Rev Respir Dis 1988;138:850-855.

26. McGavin CR, Artvinli M, Naoe $\mathrm{H}$ et al. Dyspnea, disability, and distance walked: Comparison of estimates of exercise performance in respiratory disease. Brit Med J 1978;2:241-243.

27. Mungall IPF, Hainsworth R. Assessment of respiratory function in patients with chronic obstructive airways disease. Thorax 1979;34:254-258.

28. Swinburn CR, Wakefield JM, Jones PW. Performance, ventilation, and oxy gen consumption in three different types of exercise tests in patients with chronic obstructive lung disease. Thorax 1985;40:581-586.

29. Knox AJ, Morrison JFJ, Muers MF. Reproducibility of walking test results in chronic obstructive airways diseasc. Thorax 1988;43:388-392.

30. Engle VF. The relationship of movement and time to older adults' functional health. Res Nurs Health 1986;9:123-129.

31. Brandstater ME, de Bruin H, Gowland $\mathrm{C}$ et al. Hemiplegic gait: Analysis of temporal variables. Arch Phys Med Rehabil 1983;64:583-587.

32. Dettmann MA, Linder MT, Sepic SB. Relationships among walking performance, postural stability, and functional assessments of the hemiplegic patient. Am J Phys Med 1987;66:77-90.

33. Inman VT, Ralston HJ, Todd F. Human Walking. Baltimore, MD: Williams \& Wilkins, 1981.

34. Himann JE, Cunningham DA, Rechnitzer PA et al. Age-related changes in speed of walking. Med Sci Sports Exerc 1988;20:161-166. 
35. Dobbs RJ, Charlett A, Bowes SC; et al. Is this walk normal? Age Ageing 1993;22:27-30.

36. Bendall MJ, Bassey EJ, Pearson MR. Factors affecting walking speed of elderly people. Age Ageing 1989;18:327-332.

37. Ellble RJ, Thomas SS, Higgins $\mathrm{C}$ et al. Stride-dependent changes in gait of older people. J Neurol 1991;2.38:1-5.

38. Ferrandez A, Pailhous J, Durup M. Slowness in elderly gait. Exp Aging Rus 1990;16:79-89.

39. Blanke DJ, Hageman PA. Comparison of gait of young men and elderly men. Phys Ther 1989;69:144-148.

40. Cunningham DA, Rechnitzer PA, Pearce ME et al. Detcrminants of selfselected walking pace across ages 19-66. J Gerontol 1982;37:560-564.

41. Finley FR, Cody KA, Finzie RV. Locomotion patterns in elderly women. Arch Phys Med Rehabil 1969;50:140-146.

42. Hageman PA, Blanke DJ. Comparison of gait of young women and elderly women. Phys Ther 1986;66:1382-1387.

43. Imms FJ, Edholm $O C_{i}$. Studies of gait and mobility in the elderly. Age Ageing $1981 ; 10: 147-156$.

44. Kaneko M, Morimoto $Y$, Kimura $M$ et al. A kinematic analysis of walking and physical finess testing in elderly women. Can J Sport Sci 1991;16:223228 .

45. Leiper (I, Craik RI. Relationships between physical activity and temporaldistance characteristics of walking in elderly women. Phys Ther 1991;71:791-80.3.

46. Lundgren-I.indquist B, Aniansson A, Rundgren A. Functional studies in 79 year olds. III. Walking performance and climbing capacity. Scand J Rehabil Med 1983;15:125-131.

47. Martin PE, Rothstein DE, Larish DD. Effects of age and physical activity status on the speed-aerobic demand relationship of walking. J Appl Physiol 1992;73:200-206.

48. Murray MP, Kory RC, Clarkson $\mathrm{BH}$. Walking patterns in healthy old men. J Gerontol 1969;24:169-178.

49. Oberg T, Karsznia A, Oberg K. Basic gait parameters: Reference data for normal subjects 10-79 years of age. J Rehabil Res Dev 1993;30:210-233.

50. Ostrosky KM, VanSwearingen JM, Burdett RG et al. A comparison of gait characteristics in young and old subjects. Phys Ther 1994;74:637-646.

51 . Williams $\mathrm{K}$, Bird $\mathrm{M}$. The aging mover: A preliminary report on constraints to action. Int J Aging Hum Dev 1992;34:241-255.

52. Woo J, Ho SC, Lau J et al. Agc-associated gait changes in the elderly: Pathological or physiological? Neurocpidemiology 1995;14:65-71.

53. Winter DA, Patla AE, Frank JS et al. Biomechanical walking changes in the fit and healthy elderly. Phys Ther 1990;70:340-347.

54. Gabell A, Nayak USL. The effect of age on variability of gait. J Gerontol 1984:39:662-666

55. Jansen EC, Vitras D, Hellberg $S$ et al. Normal gait of young and old men and women. Acta Orthop Scand 1982;53:193-196.

56. Craik RL, Oastis CA. Gait assessment in the clinic: Issues and approaches. In: Rothstcin JM, ed. Measurement in Physical Therapy. New York: Churchill Livingstone, 198.5, pp 169-205.

57. Murray MP, Mollinger LA, Gardner GM et al. Kinematic and EMG patterns during slow, frec, and fast walking. J Orthop Res 1984;2:272-280.

58. Oberg $T$, Karsznia A, Oberg K. Joint angle parameters in gait: Reference data for normal subjects 10-79 years of age. J Rehabil Res Dev 199.3;30:210-233

59. Crowninshield RD, Brand RA, Johnston RC.. The effects of walking velocity and age on hip kinematies and kinetics. Clin Orthop 1978;132:140144

60. O'Brien M, Power K, Sanford $S$ er al. Temporal gait patterns in healthy young and elderly females. Physiother Can 1983;35:323-326.

61. Larish DD, Martin P'E, Mungiole $M$. Characteristic patterns of gait in the healthy old. In: Joseph JA, cd. Central Determinants of Age-related Declines in Motor Function. New York: Annals of the New York Academy of Sciences, 1988, pp 18-32.

62. Murray MP, Drought AB, Kory RC: Walking patterns of normal men. J Bone Joint Surg Am 1964;46:335-360.

63. Dobbs RJ, L.ubel DD, Charlett A tt al. Hypothesis: Age-associated changes in gait represent, in part, a tendency towards parkinsonism. Age Ageing 1992;21:221-225

64. Guimares RM, Isaacs B. Characteristics of the gait in old people who fall. Int Rehabil Med 1980;2:177-180.

65. Bowes SC, Charlett $A$, Dobbs $R J$ et al. Gait in relation to ageing and idiopathic parkinsonism. Scand J Rehabil Med 1992;24:181-186.

66. Knutsson $\mathrm{E}$., An analysis of parkinsonian gait. Brain 1972;95:475-486.

67. Murray MP. Gait as a total pattern of movement. Am J Phys Med 1967;46:290-333.

68. Murray MP, Sepic SB, Gardner GM et al. Walking patterns of men with parkinsonism. Am J l'hys Med 1978;57:278-294.
69. Knutsson E, Richard C. Different types of disturbed motor control in gait of hemiparctic patients. Brain 1979;102:405-430.

70. Peat M, Dubo HI, Winter DA ct al. Flectromyographic temporal analysis of gait: Hemiplegic locomotion. Arch Phys Med Rehabil 1976;57:421-425.

71. Perry J. The mechanics of walking in hemiplegia. Clin Orthop 1969;63:2331.

72. Wall JC, Turnbull GI. Gait asymmetries in residual hemiplegia. Arch Phys Med Rehabil 1986;67:550-553.

73. Knutsson E, Lying-I'unellu. Gait apraxia in normal-pressure hydrocephalus: Patterns of movement and muscle activation. Neurology $1985 ; 35: 155-$ 160.

74. Sorenson PS, Jansen EC, Gjerris F. Motor disturbances in normal-pressure hydrocephalus. Special reference to stance and gait. Arch Neurol 1986;43:34-38.

75. Sudarsky L, Simon S. Grait disorder in late-life hydrocephalus. Arch Neurol 1987;44:263-267.

76. Mueller MJ, Minor SD, Sahrmann SA et al. Differences in the gait characteristics of patients with diabetes and peripheral neuropathy compared to age-matched controls. Phys Ther 1994;74:299-313.

77. Messier SP, Loeser RF, Hoover JL et al. Osteoarthritis of the knee: Effects on gait, strength, and flexibility. Arch Phys Med Rehabil 1992;73:29-36.

78. Messier SP. Osteoarthritis of the knce and associated factors of age and obesity: Effects on gait. Med Sci Sports Exerc 1994;26:1446-14.52.

79. Smidt GL, Wadsworth JB. Floor reaction forces during gait: Comparison of patients with hip discase and normal subjects. Phys Ther 1973;53:10561062.

80. Davies SW, Greig CA, Jordan SL et al. Short-stepping gait in severe heart failure. Br Heart J 1992;68:469-472.

81. Hausdorff JM, Forman DE, Ladin $Z$ et al. Increased walking variability in elderly persons with congestive heart failure. J Am Geriatr Soc 1994:42:1056-1061.

82. Blin O, Ferrandez AM, Serratrice G. Quantitative analysis of gait in Parkinson patients: Increased variability of stride length. J Neurol Sci 1990;98:91-97.

83. Stauffer RN, Chao EYS, Gyory AN. Biomechanical gait analysis of the diseased knee joint. Clin Orthop 1977;126:246-255.

84. Murray MP, Gore DR, Clarkson $\mathrm{BH}$ et al. Walking patterns of patients with unilateral hip pain due to osteoarthritis and avascular necrosis. J Bone Joint Surg Am 1971;53:259-273.

85. Murray MP, Gore DR, Sepic SB et al. Antalgic maneuvers during walking in men with unilateral knee disability. Clin Orthop 1985;199:192-200.

86. Bassey EJ, Fiatarone MA, O'Neill EF et al. Leg extensor power and functional performance in very old men and women. Clin Sci 1992;82:321-327.

87. Bassey EJ, Bendall MJ, Pearson M. Muscle strength in the triceps surae and objectively measured customary walking activity in mean and women over 65 years of age. Clin Sci 1988;74:85-89.

88. Buchner DM, de Lateur BJ. 'The importance of skeletal muscle strength to physical function in older adults. Ann Behav Med 1991;13:91-98.

89. Bohannon RW, Andrews AW. Correlation of knee extensor muscle torque and spasticity with gait speed in patients with stroke. Arch Phys Med Reha bil 1990;71:330-3.33.

90. Olncy SJ, Griffin MP, McBride ID. Temporal, kinematic, and kinctic variables related to gait speed in subjects with hemiplegia: $A$ regression approach. Phys Ther 1994;74:872-885.

91. Folstein MF, Folstein SE, McHugh PR. "Mini-Mental State": A practical method for grading the cognitive state of patients for the clinician. J Psychiatr Res 1975;12:189-198.

92. Alexander NB, Mollo JM, Giordani B et al. Maintenance of balance, gait patterns and obstacle clearance in Alzhcimer's disease. Neurology 1995;45:908-914.

93. Visser H. Gait and balance in senile dementia of Alzheimer's type. Age Ageing $1983 ; 12: 296-301$

94. Sloman L, Berridge M, Homatidis MA et al. Gait patterns of depressed patients and normal subjects. Am J Psychiatry 1982;139:94-97.

95. Fried AV, Cwikel J, Ring $\mathrm{H}$ et al. ELCAM-Extra-laboratory gait assessment method; Identification of risk factors for fall among the elderly at home. Int Disabil Stud 1990;12:161-164.

96. Sloman L, Pierrynowski M, Berridge $M$ et al. Mood depressive illness, and gait patterns. Can J Psychiatry 1987;32:190-193.

97. Guyatt GH, Pugsley SO, Sullivan MJ et al. Effect of encouragement on walking test performance. Thorax 1984;39:818-822.

98. Hopkins DR, Murrah B, Hoeger WWK et al. Effect of low-impact aerobic dance on the functional fitness of elderly women. Gerontologist 1990;30:189-192.

99. Judge JO, Whipple RH, Wolfson LI. Effects of resistive and balance exercises on isokinetic strength in older persons. J Am Geriatr Soc $1994 ; 42: 937-946$. 
100. Judge JO, Underwood M, Gennosa T. Exercise to improve gait velocity in older persons. Arch Phys Med Rehabil 1993;74:400-406.

101. Brown M, Holloszy JO. Effects of a low intensity exercise program on selected physical performance characteristics of 60-71 year olds. Aging 1991;3:129-139.

102. 'Topp R, Mikesky A, Wigglesworth J et al. The effect of a 12-week dynamic resistance strength training program on gait velocity and balance of older adults. Gerontologist 1993;33:501-506.

103. Fiatarone MA, Marks EC, Ryan ND et al. High-intensity strength training in nonagenarians. Effects on skeletal muscle. JAMA 1990;263:3029 -30.34

104. Fiatarone MA, O'Neill EF, Ryan ND et al. Exercise training and nutritional supplementation for physical frailty in very elderly people. $\mathrm{N}$ Engl J Med 1994;330:1769-1775.

105. Sauvage LR, Myklebust BM, Crow-Pan J et al. A clinical trial of strengthening and aerobic exercise to improve gait and balance in elderly male nursing home residents. Am J Phys Med Rehabil 1992;71:333-342.

106. Tinetti ME, Speechley M, Ginter (FF. Risk factors for falls among elderly persons living in the community. N Engl J Med 1988;319:1701-1707.

107. Lipsitz LA, Jonsson PV, Kelley MM et al. Causes and correlates of recurrent falls in ambulatory frail elderly. J Gerontol 1991;46:M114-122.

108. Judge JO, King MB, Whipple $\mathrm{R}$ et al. Dynamic balance in older persons: Effects of reduced visual and proprioceptive input. J Gerontol 1995;50A:M263-270.

109. Yack HJ, Berger RC. Dynamic stability in the elderly: Identifying a possible measure. J Gerontol 1993;48:M225-230.

110. Wall JC, Hogan DB, Turnbull (II et al. The kinematics of idiopathic gait disorder. Scand J Rehab Med 1991;23:159-164.

111. Wolfson 1, Whipple R, Amerman P et al. Gait assessment in the elderly: A gait abnormality rating scale and its relation to falls. J Gerontol 1990;45:M12-19.

112. Feltner ME, MacRae P(; McNitt-Gray JL. Quantitative gait assessment as a predictor of prospective and retrospective falls in community-dwelling older women. Arch Phys Med Rehabil 1994;75:447-453.

113. Gehlsen GM, Whaley MI1. Falls in the elderly: Part 1, Gait. Arch Phys Med Rehabil 1990;71:735-738.

114. Heitmann DK, Gossman MR, Shaddeau SA et al. Balance performance and step width in noninstitutionalized, elderly, female fallers and nonfallers. Phys Ther 1989;69:923-931.

115. Tinetti ME, Mendes de Leon CF, Doucette JT et al. Fear of falling and fallrelated efficacy in relationship to functioning among community-living elders. J Gerontol 1994;49:M140-147.

116. Murphy J, lsaacs B. The post-fall syndrome. Gerontology 1982;28:265270 .

117. Marks I. Space "phobia": A pseudo-agoraphobic syndrome. J Neurol Neurosurg Psychiatry 1981;44:387-391.

118. Bloem BR, Haan J, Lagaay AM et al. Investigation of gait in elderly subjects over 88 years of age. J Geriatr Psychiatry Neurol 1992;5:78-84.

119. Tinetti ME. Performance-oriented assessment of mobility problems in elderly patients. J Am Geriatr Soc 1986;34:119-126.

120. Sudarsky L, Ronthal M. Gait disorders among elderly patients: A survey study of 50 paticnts. Arch Neurol 1983;40:740-743

121. Fuh JL, Lin KN, Wang SJ et al. Neurologic diseases presenting with gait impairment in the elderly. J Geriatr Psychiatry Neurol 1994;7:89-92.

122. Hough JC, McHenry MP, Kammer I.M. Gait disorders in the elderly. Am Fam Physician 1987;30:191-196.

123. Kotsoris $H$, Barclay L.L., Kheyfets $S$ et al. Urinary and gait disturbances as markers of early multi-infarct dementia. Stroke 1987;18:138-141.

124. Hachinski VC, Potter P, Merksey H. Leuko-araiosis. Arch Neurol 1987;44:21-23.

125. George A, de Leon MJ, Gentes Cl et al. Leukoencephalopathy in normal and pathologic aging: 1. CT of brain lucencies. AJNR Am J Neuroradiol $1986 ; 7: 561-566$

126. Hennerici MG, Oster M, Cohen S et al. Are gait disturbances and white matter degeneration early indicators of vascular dementia? Dementia 1994;5:197-202.

127. Stcingart A, Hachinski VC, Lau $C$ et al. Cognitive and neurologic findings in subjects with diffuse white matter lucencies on computed tomographic scan (leuko-araiosis). Arch Neurol 1987;44:32-35.

128. Masdeu JC, Wolfson $L$, Lantos $G$ et al. Brain white-matter changes in the elderly prone to falling. Arch Neurol 1989;46:1292-1296.

129. Meyer JS, Kawamura J, Terayama Y. White matter lesions in the elderly. J Neurol Sci 1992;110:1-7.

130. Hendric HC, Farlow MR, Austrom MG et al. Foci of increased T2 signal intensity on brain MR scans of healthy elderly subjects. AJNR Am J Neuroradiol 1989;10:703-707.

131. Chui HC, Victoroff JI, Margolin D et al. Criteria for the diagnosis of isch emic vascular dementia proposed by the State of California Alzheimer's
Disease diagnostic and treatment centers. Neurology 1992;42:473-480.

132. Babikian V, Ropper AH. Binswanger's disease: A review. Stroke 1987;18:2-12.

133. Caplan LR, Schoene WC. Clinical features of subcortical arteriosclerotic encephalopathy (Binswanger's discase). Neurology 1978;28:1206-1215.

134. Roman GC. Senile dementia of the Binswanger type. A vascular form of dementia in the elderly. JAMA 1987;258:1782-1788.

13.5. Sudarsky L. Geriatrics: Gait disorders in the elderly. N Engl J Med 1990;322:1441-1446.

136. Thompson PD, Marsden CD. Gait disorder of subcortical arteriosclerotic encephalopathy: Binswanger's Disease. Mov Disord 1987;2:1-8.

137. Loizou LA, Kendall BE, Marshall J. Subcortical arteriosclerotic encephalopathy: A clinical and radiological investigation. J Neurol Neurosurg Psy chiatry 1981;44:294-304.

138. Adams RD, Fisher CM, Hakim $S$ et al. Symptomatic occult hydrocephalus with "normal" cerebrospinal fluid pressure: A treatable syndrome. N Engl J Med 1965;273:117-126.

139. Rasker JJ, Jansen ENH, Haan J et al. Normal-pressure hydrocephalus in rheumatic patients. A diagnostic pitfall. N Engl J Med 1985;312:1239_ 1241 .

140. Vanneste J, Augustin P, Dirven C ct al. Shunting normal-pressurc hydrocephalus: Do the benefits outweigh the risks? Neurology 1992:42:54-59.

141. Mulrow $C D$, Feussner JR, Williams $B C$ et al. The value of clinical findings in the detection of normal pressure hydrocephalus. J Gerontol 1987:42:277-279.

142. Fisher CM. Hydrocephalus as a cause of gait disturbances in the elderly. Neurology 1982;32:1358-1363.

143. Nutt JG, Marsden CD, Thompson PD. Human walking and higher-level gait disorders, particularly in the elderly. Neurology 1993;43:268-279.

144. Black PM. Idiopathic normal-pressure hydrocephalus. Results of shunting in 62 patients. J Neurosurg 1980;52:371-377.

145. Sudarsky I, Simon S. Gait disorder in late-life hydrocephalus. Arch Neurol 1987;44:263-267.

146. Estanol BV. Gait apraxia in communicating hydrocephalus. J Neurol Neurosurg Psychiatry 1981;44:305-308.

147. Clarfield AM. Normal-pressure hydrocephalus: Saga or swamp? JAMA 1989;262:2.592-2.593.

148. Earnest MP, Fahn S, Karp JH et al. Normal pressure hydrocephalus and hypertensive cerebrovascular disease. Arch Neurol 1974;31:262-266.

149. Beck WS. Neuropsychiatric consequences of cobalamin deficiency. Adv Intern Med 1991;36:33-56.

150. Fine EJ, Soria ED. Myths about vitamin $B_{12}$ deficiency. South Med J 1991;84:1475-1481.

151. Healton EB, Savage DG, Brust JCM et al. Neurologic aspects of cobalamin deficiency. Medicine (Baltimore) 1991;70:229-245.

152. Shorvon SD, Carney MWP, Chanarin I et al. The neuropsychiatry of megaloblastic anemia. Br Med J 1980;281:1036-1038.

153. Lindenbaum J, Healton EB, Savage DG et al. Neuropsychiatric disorders caused by cobalamin deficiency in the absence of anemia or macrocytosis. N Engl J Med 1988;318:1720-1728.

154. Botez Ml, Peyronnard JM, Bachevalier J et al. Polyneuropathy and folate deficiency. Arch Neurol 1978;35:581-584.

155. Manzoor M, Runcie J. Folate-responsive neuropathy: Report of 10 cases. Br Med J 1976;1:1176-1178.

156. Koller WC, Glatt SL, Fox JH et al. Cerebellar atrophy: Relationship to aging and cerchral atrophy. Neurology 1981;31:1486-1488.

157. Cunha UV. Differential diagnosis of gait disorders in the elderly. Geriatrics 1988;43:33-42.

158. Cremer GM, Goldstein NP, Paris J. Myxedema and ataxia. Neurology $1969 ; 19: 37-46$.

159. Jellinek EH, Kelly RE. Cerebellar syndrome in myxoedema. Lancet 1960;2:225-227.

160. Price TR, Netsky MG. Myxedema and ataxia. Neurology 1966;16:957962.

161. Beghi E, Delodovici ML, Bogliun G et al. Hypothyroidism and polyneuropathy. J Neurol Neurosurg Psychiatry 1989;52:1420-142.3.

162. Dyck PJ, Lambert EH. Polyneuropathy associated with hypothyroidism. J Neuropath Exp Neurol 1970;29:631-658.

163. Meier C, Bischoff A. Polyneuropathy in hypothyroidis. Clinical and nerve biopsy study of 4 cases. J Neurol 1977;215:103-114.

164. Fessel WJ. Myopathy of hypothyroidism. Ann Rheum Dis 1968;27:590596.

165. Scarpalezos S, Lygidakis C, Papageorgiou C et al. Neural and muscular manifestations of hypothyroidism. Arch Neurol 1973;29:140-144.

166. Nickel SN, Frame B. Nervous and muscular systems in myxedema. J Chronic Dis 1961;14:570-580. 
167. Ludin HP, Spiess H, Koenig MP. Neuromuscular dysfunction associated with thyrotoxicosis. Eur Neurol 1969;2:269-278.

168. Bulens C. Neurologic complications of hyperthyroidisn: Remission of spastic paraplegia, dementia and optic neuropathy. Arch Neurol 1981;38:669670.

169. Florin T, Walls RS. Neurological complications of thyrotoxicosis in the elderly. Ann Neurol 1984;15:608.

170. Ravera JJ, Cervino JM, Fernandez G et al. Two cases of Graves' disease with signs of a pyramidal lesion. Improvement in neurologic signs during treatment with antithyroid drugs. J Clin Endocronol Metab 1960;20:876880 .

171. Critchley M. On senile disorders of gait, including the so-called "senile paraplegia." Geriatrics 1948;3:364-370.

172. Koller WC, Wilson RS, Glatt SL. et al. Senile gait: Correlation with computed tomographic scans. Ann Neurol 1983;13:343-344.

173. Elble RJ, Hughes L, Higgins C. The syndrome of senile gait. J Neurol 1992;239:71-7.5

174. Hogan DB, Berman P, Fox FA et al. Idiopathic gait disorders of the elderly. Clin Rehabil 1987;1:17-22.

17.5. Sabin TD. Biologic aspects of falls and mobility limitations in the elderly. J Am Geriatr Soc 1982;30:51-58.

176. Lempert T, Dicterich, Huppert D et al. Psychogenic disorders in neurology: Frequency and clinical spectrum. Acta Neurol Scand 1990;82:335-340.

177. Lempert T, Brandt T, Dicterich $M$ et al. How to identify psychogenic disorders of stance and gait. J Neurol 1991;2.38:140-146.

178. Sinet M, Fisenberg MS. Two unusual gait disturbances: astasia abasia and camptocormia. Arch Phys Med Rehabil 1990;71:1078-1080.

179. Keane JR. Hysterical gait disorders: 60 cases. Neurology 1989;39:586589.

180. Chui HC. Dementia. A review emphasizing clinicopathologic correlation and brain-behavior relationships. Arch Neurol 1989;46:806-814.

181. Korrke FJ, Lehmann JF. Krusen's Handbook of Physical Medicine and Rehabilitation, 4th Ed. Philadelphia: WB Saunders, 1990.

182. Perry J. Gait Analysis: Normal and Pathological Function. Thorofare, NJ: Slack, 1992.

183. Benvenuti F, Ferrucci l., Guralnik JM et al. Foot pain and disability in older persons: An cpidemiologic survey. J Am Geriatr Soc 1995;43:479_ 485 .

184. Dubinsky RM, Jankovic J. Progressive supranuclear palsy and a multiinfarct state. Neurology 1987;37:570-576.

185. Masdeu JC, Gorelick PB. Thalamic astasia: Inability to stand after unilateral thalamic lesions. Ann Neurol 1988;23:596-603.

186. Labadie EL, Awerbuch Gl, Hamilton RH et al. Falling and postural deficits due to acute unilateral basal ganglia lesions. Arch Neurol 1989;46:492496.

187. Felice KJ, Keilson GR, Schwartz WJ. 'Rubral' gait ataxia. Neurology 1990;40:1004-1005.

188. Fitzgerald PM, Jankovic J. Lower body parkinsonism: Evidence for vascular etiology. Mov Disord 1989;4:249-260.

189. King MB, Tinetti ME. Falls in community-dwelling older persons. J Am Geriatr Soc 1995;43:1146-1154.

190. Krebs DE, Edelstein JE, Fishman S. Reliability of observational kinematic gait analysis. Phys Ther 1985;6.5:1027-1033.

191. Eastlack ME, Arvidson J, Snyder-Mackler L et al. Interrater reliability of videotaped observational gait-analysis assessments. Phys Ther $1991 ; 71: 465-472$

192. Holden MK, Gill KM, Magliozzi MR et al. Clinical gait assessment in the neurologically impaired. Reliability and meaningfulness. Phys Ther 1984;64:35-40.

193. Holden MK, Gill KM, Magliozzi MR. (iait assessment for neurologically impaired patients. Standards for outcome assessment. Phys Ther 1986;66:1.530-1539.

194. Nelson AJ. Functional ambulation profile. Phys Ther 1974;54:1059-1065.

195. Olney SJ, Elkin ND, Lowe ['J et al. An ambulation profile for clinical gait evaluation. Physiother Can 1979;31:85-90.

196. Chen HC, Ashton-Miller JA, Alexander NB et al. Stepping over obstacles: Gait patterns of healthy young and old adults. J Gerontol 1991;46:M196203.

197. Hendry A, Gilchrist W, Duncan G et al. Measurement of walking speed in elderly inpatients. Med Biol Eng Comput 1990;28:602-604.

198. Smith DC, Evans AL, Gilchrist W. Novel instrument for measuring the walking speed of elderly patients. Med Biol Eng Comput 1990;28:605607.

199. Chen HC, Ashton-Miller JA, Alexander NB et al. Effects of age and available response time on ability to step over an obstacle. J Gerontol 1994:49:M227-233
200. Robinson JL, Smidt GL. Quantitative gait evaluation in the clinic. Phys Ther 1981;61:351-3.53.

201. Stuherg W, Straw L, Devine L. Validity of visually recorded temporaldistance measures at selected walking velocities for gait analysis. Percept Mot Skills 1990;70:323-333.

202. Boenig DD. Evaluation of a clinical method of gait analysis. Phys Ther 1977;57:795-798.

203. Klenerman L, Dobbs RJ, Weller C. Bringing gait analysis out of the laboratory and into the clinic. Age Ageing 1988;17:397-400.

204. Hill KD, Goldie PA, Baker PA et al. Retest reliability of the temporal and distance characteristics of hemiplegic gait using a footswitch system. Arch Phys Med Rehabil 1994;75:577-583.

205. Mizrahi J, Susak Z, Heller L ct al. Variation of time-distance parameters of the stride as related to clinical gait improvements in hemiplegics. Scand J Rehab Med 1982;14:13.3-140.

206. Smidt GL, Deusinger RH, Arora J et al. An automated accelerometry system for gait analysis. J Biomech 1977;10:367-375.

207. Smidt Gl, Mommens MA. System of reporting and comparing influence of ambulatory aids on gait. Phys Ther 1980;60:551-558.

208. Pandy $M G$, Berme N. Quantitative assessment of gait determinants during single stance via a three-dimensional model - Part 2. Pathological gait. J Biomech 1989;22:72.5-733.

209. Saunders JB, Inman VT, Fberhart HD et al. The major determinants in normal and pathological gait. J Bone Joint Surg Am 35;19.53:543-558.

210. Hughes KA, Bell F. Visual assessment of hemiplegic gait following stroke: Pilot study. Arch Phys Med Rehabil 1994;75:1100-1107.

211. Begg RK, Wytch R, Major RE. Instrumentation used in clinical gait studies: A review. J Med Eng Technol 1989;13:290-295.

212. Stanic U, Bajd T, Valencic $V$ et al. Standardization of kinematic gait measurements and automatic pathological gait pattern diagnostics. Scand J Rehabil Med 1977;9:95-105.

213. Cerny K. Pathomechanics of stance. Clinical concepts for analysis. Phys Ther 1984;64:1851-1859.

214. Gronley JK, Perry J. Gait analysis techniques. Rancho Los Amigos Hospital Gait Laboratory. Phys Ther 1984;64:1831-1838.

215. Hargreaves P, Scales JT. Clinical assessment of gait using load measuring footwear. Acta Orthop Scand 1975;46:877-895.

216. Hausdorff JM, Ladin Z, Wei JY. Footswitch system for measurement of the temporal parameters of gait. J Biomech 1995;28:347-351.

217. Hoodless DJ, Stainer $\mathrm{K}$, Savic $\mathrm{N}$ et al. Reduced customary activity in chronic heart failurc: Assessment with a new shoe-mounted pedometer. Int J Cardiol 1994;43:39-42.

218. Jansen EC. Postural stability by foot-to-ground force measurement. Dan Med Bull 1988;35:479-493

219. Waters RL, Hislop HJ, Perry J et al. Energetics: Application to the study and management of locomotor disabilitics. Orthop Clin North Am 1978;9:351-377.

220. Mackinnon CD, Winter DA. Control of whole body balance in the frontal plane during human walking. J Biomech 1993;26:633-644.

221. Winter DA. Biomechanical motor patterns in normal walking. I Mot Behav $1983 ; 15: 302-330$.

222. Murray MP, Seireg AH, Scholz RC.. A survey of the time, magnitude, and oricntation of forces applicd to walking sticks used by disabled men. Am J Phys Med 1969b;49:1-13.

223. Ely DD, Smidt GL. Effect of cane on variables of gait for patients with hip disorders. Phys Ther 1977;57:507-512.

224. Pardo RD, Deathe AB, Winter DA. Walker user risk index. A method for quantifying stability in walker users. Am J Phys Med Rehabil 199.3;72:301-305

225. Winter DA. Concerning the scientific basis for the diagnosis of pathological gait and for rehabilitation protocols. Physiother Can 1985;37:245-252.

226. Abransky $\mathrm{O}$. Common and uncommon neurological manifestations as presenting symptoms of vitamin-B $B_{12}$ deficiency. J Am Geriatr Soc 1972;20:9.396.

227. Jacobs I,G, Bloom HG, Behrman FZ. Mania and a gait disorder due to cobalamin deficiency. J Am (ieriatr Soc 1990;38:473-474.

228. Pennypacker LC, Allen RH, Kelly JP et al. High prevalence of cobalamin deficiency in elderly outpatients. J Am Geriatr Soc 1992:40:1197-1204.

229. Reynolds $\mathrm{EH}$, Rothfeld P, Pincus JH. Neurological disease associated with folate deficiency. Br Med J 1973;2:398-400.

230. Folic acid and the nervous system (editorial). Lancet 1976;2:836.

231. Ferrandez AM, Blin O. A comparison between the effect of intentional modulations and the action of L-Dopa on gait in Parkinson's disease. Behav Brain Res 1991;45:177-183.

232. Blin O, Ferrandez AM, Pailhous J et al. Dopa-sensitive and dopa-resistant gait parameters in Parkinson's disease. J Neurol Sci 1991;103:51-54. 
233. Schnitzer TJ, Popovich JM, Andersson GBJ et al. Effect of piroxicam on gait in patients with ostcoarthritis of the knee. Arthritis Rheum 1993; 36:1207-1213

234. Blin (), Pailhous J, Lafforgue P et al. Quantitative analysis of walking in patients with knee osteoarthritis: A method of assessing the effectiveness of non-steroidal anti-inflammatory treatment. Ann Rheum Dis 1990;49:990993.

235. Pestronk A, Choksi R, Bieser $K$ et al. Treatable gait disorder and polyneuropathy associated with high titer serum IgM binding to antigens that copurify with myelin-associated glycoprotein. Muscle Nerve 1994;17:12931300.

236. Comella $\mathrm{Cl}$., Stebbins GT, Brown-Toms $\mathrm{N}$ et al. Physical therapy and Parkinson's disease: A controlled clinical trial. Neurology 1994:44:376-378.

237. Gibberd FB, Page NGR, Spencer KM et al. Controlled trial of physiotherapy and occupational therapy for Parkinson's disease. Br Med J $1981 ; 282: 1196$.

238. Formisano R, Pratesi L, Modarelli FT et al. Rehabilitation and Parkinson's disease. Scand J Rehab Med 1992;24:157-160.

239. Palmer SS, Mortimer JA, Webster DD et al. Exercise therapy for Parkinson's diseasc. Arch Phys Med Rehabil 1986;67:741-745.

240. Dunne JW, Hankey GJ, Edis RH. Parkinsonism: Upturned walking stick as an aid to locomotion. Arch Phys Med Rehabil 1987;68:380-381.

241. Bagley S, Kelly B, Tunnicliffe $N$ et al. The effect of visual cues on the gait of independently mobile Parkinson's disease patients. Physiotherapy $1991 ; 77: 415-420$.

242. Morris ME, lansek $R$, Matyas TA et al. The pathogenesis of gait hypokinesia in Parkinson's disease. Brain 1994;117:1169-1181.

243. Kovar PA, Allegrante JP, MacKenzie CR et al. Supervised fitness walking in patients with osteoarthritis of the knee. A randomized, controlled trial. Ann Intern Med 1992;116:529-534.

244. Peterson MCFE, Kovar-Toledano PA, Otis JC et al. Effect of a walking program on gait characteristics in patients with osteoarthritis. Arthritis Care Res 1993;6:11-16.

245. Fisher NM, Gresham GE, Abrams M et al. Quantitative effects of physical therapy on muscular and functional performance in subjects with osteoarthritis of the knees. Arch Phys Med Rehabil 1993;74:840-847.

246. Minor MA, Hewett JE, Webel RR ct al. Efficacy of physical conditioning exercise in patients with rheumatoid arthritis and osteoarthritis. Arthritis Rheum 1989;32:1396-1405.

247. Wade DT, Wood VA, Hewer RI.. Recovery after stroke-the first 3 months. J Neurol Neurosurg Psychiarry 1985;48:7-13.

248. Wade DT, Wood VA, Heller A et al. Walking after stroke. Measurement and recovery over the first 3 months. Scand J Rehabil Med 1987;19:25-30.

249. Jorgensen HS, Nakayama H, Raaschou $\mathrm{HO}$ et al. Recovery of walking function in stroke patients: The Copenhagen Stroke Study. Arch Phys Med Rehabil 1995;76:27-32.

250. Hesse SA, Jahnke MT, Bertelt CM et al. Gait outcome in ambulatory hemiparetic patients after a 4-wcek comprehensive rehabilitation program and prognostic factors. Stroke 1994;2.5:1999-2004.

251. Wade DT, Collen FM, Robb (iF et al. Physiotherapy late after stroke and mobility. Br Med J 1992;304:609-613.

252. Murray PK. Cervical spondylotic myelopathy: A cause of gait disturbance and urinary incontinence in older persons. J Am Geriatr Soc 1984;32:3243.30

253. Turner JA, Ersek M, Herron L et al. Surgery for lumbar spinal stenosis. Attempted meta-analysis of the literature. Spine 1992;17:1-8.

254. Turner JA, Ersek $M$, Herron $L$ et al. Patient outcomes after lumbar spinal fusions. JAMA 1992;268:907-911.

2.55. Stucki G, Liang MH, Lipson SJ et al. Contribution of neuromuscular impairment to physical functional status in patients with lumbar spinal stenosis. J Rheumatol 1994;21:1338-1343.

256. Smith EB, Hanigan WC. Surgical results and complications in elderly patients with benign lesions of the spinal canal. J Am Geriatr Soc 1992;40:867-870

257. Yu YI., DuBoulay GH, Stevens JM et al. Computer-assisted myelography in cervical spondylotic myelopathy and radiculopathy. Brain $1986 ; 109: 259-278$

258. Nurick $S$. The natural history and the results of surgical treatment of the spinal cord disorder associated with cervical spondylosis. Brain 1972;95:101-108.

259. Epstein JA, Janin Y, Carra R et al. A comparative study of the treatment of cervical spondylotic myeloradiculopathy. Acta Neurochir (Wien) 1982;61:89-104.

260. Gregorius FK, Estrin T, Crandall PH. Cervical spondylotic radiculopathy and myclopathy. Arch Neurol 1976;33:618-625.

261. Phillips DC. Surgical treatment of myelopathy with cervical spondylosis. J Neurol Neurosurg Psychiatry 1973;36:879-884.
262. Lees F, Turner JWA. Natural history and prognosis of cervical spondylosis. Br Med J 1963;2:1607-1610.

263. Larocca $\mathrm{H}$. Cervical spondylotic myelopathy: Natural history. Spine $1988 ; 13: 854-855$.

264. Herron LD, Mangelsdorf C. Lumbar spinal stenosis: Results of surgical treatment. J Spinal Disord 1991;4:26-33.

265. Herno A, Airaksinen O, Saari T. The long-term prognosis after operation for lumbar spinal stenosis. Scand J Rehabil Med 1993;25:167-171.

266. Sanderson PI., Wood PLR. Surgery for lumbar spinal stenosis in old people. J Bone Joint Surg Br 1993;75:393-397.

267. Silvers HR, Lewis PJ, Asch HL. Decompressive lumbar laminectomy for spinal stenosis. J Neurosurg 1993;78:695-701.

268. Tuite GF, Stern JD, Doran SE et al. Outcome after laminectomy for lumba spinal stenosis. Part I: Clinical correlations. J Neurosurg 1994;81:699-706

269. Katz JN, Lipson SJ, Larson MG et al. The outcome of decompressive laminectomy for degenerative lumbar stenosis. J Bone Joint Surg Am 1991;73:809-816.

270. Simpson JM, Silveri CP, Balderston RA et al. The results of operations on the lumbar spinc in parients who have diabetes melllitus. J Bone Joint Surg Am 1993;75:182-1829.

271. Hall S, Bartleson JD, Onofrio BM et al. Lumbar spinal stenosis. Clinical features, diagnostic procedures, and results of surgical treatment in 68 patients. Ann Intern Med 1985;103:271-275.

272. Johnsson KE, Uden A, Rosen 1 . The effect of decompression on the natural course of spinal stenosis. A comparison of surgically treated and untreated patients. Spine 1991;16:615-619.

273. Jacobs L, Conti D, Kinkel WR et al. "Normal pressure" hydrocephalus. Relationship of clinical and radiographic findings to improvement following shunt surgery. JAMA 1976;2.35:510-512.

274. Graff-Radford NR, Godersky JC. Normal-pressure hydrocephalus. Onset of gait abnormality before dementia predicts good surgical outcome. Arch Neurol 1986;43:940-942.

275. Borgesen $\mathrm{SF}$, Gjerris $\mathrm{F}$. The predictive value of conductance to outflow of CSF in normal pressure hydrocephalus. Brain 1982;105:65-86.

276. Petersen RC, Mokri B, Laws ER. Surgical treatment of idiopathic hydrocephalus in elderly parients. Neurology 1985;35:307-311.

277. Raftopoulos C, Deleval J, Chaskis C et al. Cognitive recovery in idiopathic normal pressure hydrocephalus: A prospective study. Neurosurgery 1994;35:397-404.

278. Larsson A, Moonen M, Bergh AC et al. Predictive value of quantitative cisternography in normal pressure hydrocephalus. Acta Neurol Scand 1990;81:327-332.

279. Chen IH, Huang CI, Liu HC ct al. Effectiveness of shunting in patients with normal pressure hydrocephalus predicted by temporary, controlledresistance, continuous lumbar drainage: A pilot study. J Neurol Neurosurg Psychiatry 1994;57:1430-1432.

280. Sand T, Bovim G, Gimse $\mathrm{R}$ et al. Idiopathic normal pressure hydrocephalus: The CSF tap-test may predict the clinical response to shunting. Act: Neurol Scand 1994;89:311-316.

281. Wikkelso $\mathrm{C}$, Anderson $\mathrm{H}$, Blomstrand $\mathrm{C}$ et al. The clincal effect of lumbar puncture in normal pressure hydrocephalus. J Neurol Neurosurg Psychiatry 1982;45:64-69.

282. Cameron MM. Chronic subdural hematoma: A review of 114 cases. J Neurol Neurosurg Psychiatry 1978:41:834-839.

283. Goto I, Kuroiwa Y, Kitamura K. The triad of neurological manifestations in bilateral chronic subdural hematoma and normal pressure hydrocephalus. J Neurosurg Sci 1986;30:123-128.

284. Raskind R, Metcalf JS, Weiss SR et al. Chronic subdural hematoma in the elderly: A curable lesion. J Am Geriatr Soc 1968;16:451-457.

285. Patrick D, Gates PC. Chronic subdural hematoma in the elderly. Age Agcing 1984;13:367-269.

286. Brinkman JR, Perry J. Rate and range of knee motion during ambulation in healthy and arthritic subjects. Phys Ther 1985;65:1055-1060.

287. Collopy MC, Murray MP, Gardner GM et al. Kinesiologic measurements of functional performance before and after geometric total knee replacement. Clin Orthop 1977;126:196-202.

288. Kroll MA, Otis JC, Sculco TP et al. The relationship of stride characteristics to pain before and after total knee arthroplasty. Clin Orthop 1989;239:191-195.

289. Simon SR, Trieshmann HW, Burdett RG et al. Quantitative gait analysis after total knee arthroplasty for monarticular degenerative arthritis. J Bone Joint Surg Am 1983;65:605-613.

290. Laughman RK, Stauffer RN, Itstrup DM et al. Functional evaluation of total knee replacement. J Orthop Res 1984;2:307-313.

291. Andriacchi TP, Galante JO, Fermier RW. The influence of total knee replacement design on walking and stair climbing. J Bone Joint Surg Am 1982;64:1328-1335. 
292. Visuri T, Honkanen R. The influence of total hip replacement on selected activities of daily living and the use of a domestic aid. Scand J Rehabil Med 1978;10:221-225.

293. Petersen VS, Solgaard S, Simonsen B. Total hip replacement in patients aged 80 years and older. J Am Geriatr Soc 1989;37:219-222.

294. Murray MP, Gore DR, Brewer BJ et al. Comparison of functional performance after McKee-Farrar, Charnley, and Muller total hip replacement. A six month follow-up of one hundred sixty-five cases. Clin Orthop $1976 ; 121: 33-43$.

29.5. Murray MP, Gore DR, Brewer BJ et al. Joint function after total hip arthroplasty: $A$ four year follow-up of 72 cases with Charnley and Muller replacements. Clin Orthop 1981;157:119-124.

296. Stauffer RN, Smidt GL, Wadsworth JB. Clinical and biomechanical analysis of gait following Charnley total hip replacement. Clin Orthop 1974;99:70-

297. Long WT, Dorr L.D, Healy B et al. Functional recovery of noncemented total hip arthroplasty. Clin Orthop 1993;288:73-77.

298. Olsson F, Goldic I, Wykman A. Total hip replaccment. Scand J Rehabil Med 1986;18:107-116.

299. LaPlante MP, Iendershot GE, Moss AJ. Assistive Technology Devices and Home Accessibility Features: Prevalence, Payment, Need, and Trends. Ad vance Data from Vital and Health Statistics; No. 217. Hyattsville, MD: National Center for Health Statistics, 1992
300. George J, Binns VE, Clayden AD et al. Aids and adaptations for the elderly at home: Underprovided, underused, and undermaintained. Br Med J $1988 ; 296: 1365-1366$

301. Sainsbury R, Mulley GP. Walking sticks used by the elderly. Br Med J $1982 ; 284: 1751$

302. Blount WP. Don't throw away the canc. J Bone Joint Surg $\Lambda \mathrm{m}$ 1956;38:695-708

303. Mulley GP. Walking sticks. Br Med J 1988;296:475-476.

304. Edwards BG. Contralateral and ipsilateral cane usage by patients with total knee or hip replacement. Arch Phys Med Rehabil 1986;67:734-740.

305. Vargo MM, Robinson LR, Nicholas JJ. Contralateral vs ispsilateral cane use. Effects on muscles crossing the knee joint. Am J Phys Med Rehabil 1992; 71:170-176.

306. Dean E, Ross J. Relationships among cane fitting, function and falls. Phys Ther 1993;73:494-504.

307. Gitlin LN, Levine R, Geiger C. Adaptive device use by older adults with mixed disabilities. Arch Phys Med Rehabil 1993;74:149-1.52.

308. Rogers JC., Holm MB. Assistive technology device use in patients with rhcumatic disease: A literature review. Am J Occup Ther 1992;46:120127.

309. Meyer JS, Barron DW. Apraxia of gait: A clinico-physiological study. Brain 1960;8.3:261-264.

310. Denny-Brown D. The nature of apraxia. J Nerv Ment Dis 1958;126:9-31

311. Wright WB. Stammering gait. Age Ageing 1979;8:8-12.
Apraxia

Apraxia de la marche

Frontal ataxia

Magnetic foot response

Marche' a petits pas

Limb-kinetic apraxia

Parkinsonism

Petren's gait

Slipping clutch syndrome Stammering gait

Trepident abasia
Usually of gait and/or trunk due to cerebral lesion. Loss of ability to properly use lower limbs for walking and other, particularly bilateral or abstract motor leg tasks. No apparent strength, cerebellar, proprioception, or vestibular loss. (see also Meyer ${ }^{309}$ )

Inability to make purposeful leg movements and eventually stand. Related to ideomotor apraxia, disconnection between idea (perception of) walking, and the motor programs required to walk.

Disequilibrium due to frontal mass lesion, preventing unassisted stance or walking

Difficulty in picking feet off the floor.

Also termed "magnetic apraxia" or "glue footed".

Short stride, shallow steps which barely clear the ground.

Progresses to start hesitation, freezing, increasing dysequilibrium.

A gait-related version of the instinctive grasp reaction. Also involves "magnetic foot response" and "slipping clutch syndrome" (see also Denny-Brown ${ }^{310}$ ).

Arteriosclerotic, Lower-half, and Lower-body Parkinsonism. Short rapid steps, hesitating, freezing, shuffling, ataxic. Improves with sensory cues (see also Critchley ${ }^{171}$ ).

See "trepident abasia."

Rapid shuffling of feet before step can be made

Hesitancy to initiate walking or change direction, as found apparently in Parkinson's disease, cervical spondylosis, and frontal disorders (see Wright ${ }^{311}$ ).

Start hesitation, stepping in place, foot dragging, turn hesitation. Gait improves with encouragement and gentle arm pulls. 